NBER WORKING PAPER SERIES

\title{
CHILD MENTAL HEALTH AND HUMAN CAPITAL ACCUMULATION: THE CASE OF ADHD
}

Janet Currie

Mark Stabile

Working Paper 10435

http://www.nber.org/papers/w10435

\author{
NATIONAL BUREAU OF ECONOMIC RESEARCH \\ 1050 Massachusetts Avenue \\ Cambridge, MA 02138 \\ April 2004
}

The authors are grateful to the Social Science and Humanities Research Council of Canada for financial support. We thank members of the CIAR new investigators network, Bonnie Zima, and seminar participants at Princeton's Center for Health and Well-being for helpful comments, and Catherine Deri and Graciana Rucci for excellent research assistance. Janet Currie also thanks Princeton's Center for Health and Well-Being for support. The views expressed herein are those of the author(s) and not necessarily those of the National Bureau of Economic Research.

(C2004 by Janet Currie and Mark Stabile. All rights reserved. Short sections of text, not to exceed two paragraphs, may be quoted without explicit permission provided that full credit, including $(\subset$ notice, is given to the source. 
Child Mental Health and Human Capital Accumulation: The Case of ADHD

Janet Currie and Mark Stabile

NBER Working Paper No. 10435

April 2004, Revised February 2006

JEL No. I2, I1

\section{ABSTRACT}

We examine U.S. and Canadian children with symptoms of Attention Deficit Hyperactivity Disorder (ADHD), the most common child mental health problem. ADHD increases the probability of delinquency and grade repetition, reduces future reading and mathematics scores, and increases the probability of special education. The estimated effects are remarkably similar in the two countries, and are robust to many specification changes.Moreover, even moderate symptoms have large negative effects relative to the effects of poor physical health.

The probability of treatment increases with income in the U.S., but not in Canada. However, in models of outcomes, interactions between income and ADHD scores are statistically insignificant in the U.S. (except for delinquency), while in Canada these interactions indicate that higher income is protective. The U.S. results are consistent with a growing psychological literature which suggests that conventional treatments for ADHD improve behavior, but have inconsistent effects on cognitive performance.

Janet Currie

Department of Economics

UCLA

405 Hilgard Avenue

Los Angeles, CA 90095-1477

and NBER

currie@simba.sscnet.ucla.edu

Mark Stabile

Department of Economics

University of Toronto

150 St. George Street

Toronto, Canada M5S 3G7

and NBER

mark.stabile@utoronto.ca 
The prevalence and importance of child mental health problems have been increasingly recognized in recent years. For example, the 1999 U.S. Surgeon General's Report (U.S. DHHS, 1999) states that approximately one in five children and adolescents in the U.S. exhibit the signs or symptoms of mental or behavioral disorders. ${ }^{1}$ Child mental health problems, while important in their own right, also often lead directly to adult mental health problems, which are a major cause of lost work time and health care costs. ${ }^{2}$ But mental health problems may also reduce adult earnings and employment indirectly by inhibiting the child's accumulation of human capital.

While the economics literature recognizes that physical health problems can impede children's human capital accumulation (c.f. Grossman and Kaestner, 1997), the link between mental health problems and human capital accumulation has received little attention. Yet the incidence of most physical health problems among children is small, while the incidence of mental health problems is large, suggesting that these problems are likely to have a more important impact on average educational attainments (Currie, 2005).

This paper examines the experience of North American children with symptoms of Attention Deficit Hyperactivity Disorder (ADHD), the most common chronic mental health problem among young children. It is difficult to find definitive estimates of the prevalence of ADHD. Most studies are based on diagnosed cases and there is considerable controversy about whether ADHD is over (or under) diagnosed, and even about whether it is actually an "illness". Two studies based on screeners for ADHD found in large national studies found that 4 to 5

\footnotetext{
${ }^{1}$ Similarly, Offord et al. (1987) report that in the Canadian province of Ontario, $18 \%$ of children have moderate to severe emotional or behavioral problems.

${ }^{2}$ For example, Ettner, Frank and Kessler (1997) show that psychiatric disorders reduce employment and earnings among both men and women. Currie and Madrian (1999) conclude that the labor market consequences of
} 
percent of American children met the diagnostic criteria for ADHD or had clinically significant symptoms (Jensen et al., 1999; Cuffe et al., 2003). Clearly, ADHD affects large numbers of children.

The few longitudinal studies that examine the effects of ADHD on child outcomes indicate that ADHD is associated with significantly worse outcomes. But it is possible that poorer outcomes reflect other problems suffered by children with ADHD. For example, in the U.S., estimated prevalence rates are almost twice as high in families with income less than $\$ 20,000$ compared to families of higher income (Cuffe et al. 2003). ${ }^{3}$ Poor children with ADHD may also receive less effective treatment than other children, and thus be at "double jeopardy" for ill effects.

We investigate these issues using data from the Canadian National Longitudinal Survey of Children and Youth, and the American National Longitudinal Survey of Youth. Our work offers a number of new contributions. First, it is problematic to focus only on diagnosed cases. ${ }^{4}$ Instead, we focus on a set of questions administered to all children in two large nationally representative longitudinal data sets. These questions are similar to the types of screening questions outlined by American Psychiatric Association for diagnosis of ADHD. Second, we address the possibility of omitted variables bias by estimating sibling-fixed effects models. Third, we examine a range of outcomes and compare the effects of ADHD to the effects of physical health conditions. We also examine the effects of ADHD symptoms in samples of

mental health problems are large relative to the consequences of physical health problems, since the former are more likely than the latter to afflict those of working age

${ }^{3}$ Other studies that find a relationship between income and ADHD prevalence include: Korenman, Miller and Sjaastad (1995), McLeod and Shanahan (1993) Dooley et al., (1998), Dooley and Stewart (2003), Phipps and Curtis (2003), and Lipman et al. (1994). Dooley et al. (1998) argue that lone parenthood has an independent effect on incidence. 
children without any other diagnosed learning disabilities. Fourth, we ask how the effects of ADHD and the probability of treatment for ADHD are mediated by income.

We show that ADHD symptoms increase the probability of future grade repetition and special education and reduce future reading and mathematics test scores. The effects are large relative to those of physical health problems such as chronic conditions: A score at the $90^{\text {th }}$ percentile of the distribution of a hyperactivity score based on symptoms increases the probability of grade repetition by 6 percent in Canada, and by 7 percent in the U.S., while having been diagnosed with a chronic condition such as asthma does not have any significant effect.

Surprisingly, income has little effect on the probability of treatment, and the test scores of higher income children are as much affected by symptoms of ADHD as those of lower income children, though higher income children are less likely to repeat grades. We find negative effects even among children whose relatively low levels of symptoms make it unlikely that they would ever be diagnosed or treated for ADHD. This finding suggests that if better ways could be found to teach the relatively small number of children diagnosed with ADHD, many other children with lower levels of symptoms might benefit.

\section{Background and Previous Literature}

ADHD is the most common chronic mental health problem among young children, and the disorder is diagnosed in more than half of all child mental health referrals (Mannuzza and Klein, 2000). It is characterized by an inability to pay attention (inattention) and/or hyperactivity. The main diagnostic criteria for ADHD are laid out in the Diagnostic and

\footnotetext{
${ }^{4}$ For example, the incidence of diagnoses of ADHD in the U.S. may have changed in response to changes in the Social Security Insurance program over the 1990s which made it more or less difficult for children diagnosed with conditions such as ADHD to receive benefits.
} 
Statistical Manual of Mental Disorders, Fourth Edition (American Psychiatric Association, 1994). These symptoms are laid out in Appendix Table 1. To be diagnosed with ADHD, a child must have six or more symptoms; have had symptoms by age 7; and be suffering impairment in two or more settings from the symptoms (usually home and school).

ADHD can affect children's schooling attainment through several channels. First, children whose behavior is considered disruptive or inappropriate are likely to have trouble in school. Second, people with ADHD process and organize information differently than others. They characteristically have great difficulty paying attention for long periods or completing assigned tasks. On the other hand, they are often able to make creative leaps. Research on teaching methods for ADHD children is limited, but does suggest that changes in the way that information is presented (e.g. more use of color, elimination of distracting details) can help such children learn (Fiore, Becker, and Nero, 1993), and that classroom management techniques can reduce disruptive behavior (State and Quiroz, 1997).

Mannuzza and Klein (2000) review three studies of the long-term outcomes of children with ADHD from the literature in medicine and psychology. In one study, children diagnosed with ADHD were matched to controls from the same school who had never exhibited any behavior problems and had never failed a grade; in a second study, controls were recruited at the 9-year follow up from non-psychiatric patients in the same medical center who had never had behavior problems; and in a third study, ADHD children sampled from a range of San Francisco schools were compared to non-ADHD children from the same group of schools.

These comparisons consistently show that the ADHD children had worse outcomes in adolescence and young adulthood than control children. For example, they had completed less schooling and were more likely to have continuing mental health problems. However, by 
excluding children with any behavior problems from the control groups, the studies might overstate the effects of ADHD. Also, the studies do not address the possibility that the negative outcomes might be caused by other factors related to a diagnosis of ADHD, such as poverty, the presence of other learning disabilities, or the fact that many people diagnosed with ADHD end up in special education. ${ }^{5}$

There is also a literature in sociology and economics, looking at longer term consequences of a broader set of behavior problems in larger samples than are typically used in psychology. For example, Farmer $(1993,1995)$ uses data from the British National Child Development Survey (the NCDS) which follows the cohort of all British children born in a single week in March 1958, to examine the consequences of childhood "externalizing” behavioral problems on men's outcomes at age 23. She finds that children who fell into the top decile of an aggregate behavior problems score at ages 7, 11, or 16 had lower educational attainment, earnings and probabilities of employment at age $23 .{ }^{6}$ Gregg and Machin (1998) also use the NCDS data and find that behavioral problems at age 7 are related to poorer educational attainment at age 16, which in turn is associated with poor labor market outcomes at ages 23 and 33. A similar study of a cohort of all New Zealand children born between 1971 and 1973 in Dunedin found that those with behavior problems at age 7 to 9 were more likely to be unemployed at age 15 to 21 (Caspi et al., 1998). ${ }^{7}$

\footnotetext{
${ }^{5}$ These studies do not address the question of whether outcomes were better for ADHD children who were treated-in fact, there appears to be virtually no research examining the longer-term effects of treatment on achievement (Wigal et al., 1999).

${ }^{6}$ Her regressions control for parent's aspirations for the child, the type of school attended, the ability group of the child, and whether they are in special education. Hence, her analysis attempts to measure the effects of externalizing behavior over and above its effects on these determinants of educational attainment.

${ }^{7}$ Other psychological studies have examined the longer term impact of different types of behavior, such as aggression (see Richard Tremblay's many studies of a cohort of Montreal school boys). However, a survey of this
} 
Our work differs from the previous work using these cohort data sets in several respects. First, we estimate sibling fixed-effects models to control for omitted variables bias. Fixed effects methods offer a powerful way to control for unobserved or imperfectly measured characteristics of households that might be associated with both with a higher probability of ADHD and with outcomes. Second, these previous papers focus on a wide set of behavior problems that are measured using the sum of the responses to a variety of questions about children's behavior, and do not attempt to focus on any specific syndrome. ${ }^{8}$ Some of the behavior problems included in previous studies might be caused by poor performance at school, rather than vice versa. In contrast, we will show that the ADHD symptoms we focus on have negative effects even when they are measured before school age. Third, the NCDS has no data on family income during childhood, so it is not possible to examine the relationships between mental health problems, treatment, income, and outcomes. Fourth, we investigate outcomes in a much more recent cohort of children than previous studies.

\section{Data}

We use data from the Canadian National Longitudinal Survey of Children and Youth (NLSCY) and from the American NLSY. The NLSCY is a national longitudinal data set which surveyed 22,831 children ages 0 to 11 and their families beginning in 1994. Follow up surveys were conducted in 1996 and 1998. We restrict our sample to those children between the ages of 4 and 11 in 1994, since only parents of children in this age range completed the ADHD screener.

literature is beyond the scope of this paper.

${ }^{8}$ A limited amount of work has examined the consequences of specific mental health problems in adolescents. Mullahy and Sindelar (1989) examine the impact of adolescent alcoholism on earnings and employment, and conclude that the onset of alcoholism before age 18 reduces earnings and employment through its 
This restriction yields 8,332 children. Finally, for our main analyses we keep only those children whose teachers were also given the ADHD screener in 1994, which yields a sample of just under 4,000 children. Sample sizes are reduced by this criterion because children must be enrolled in school to have a teacher report, and some schools did not return completed questionnaires. We focus on the teacher responses to the screener as we felt that they would be less correlated with other unobserved characteristics of the family than the parent responses. It may be the case, however, that teacher responses are influenced by school related outcome measures. We have re-estimated all our models including all children who meet the other sample inclusion criteria, and using parental responses to the ADHD screener. The results are extremely similar to those reported below. For analyses that use Canadian math and reading test scores we have a smaller sample of approximately 2,200. ${ }^{9}$ We use the NLSCY data to ask how the hyperactivity score in 1994 affects treatment in 1994 and outcomes in 1998.

The NLSY began in 1979 with a survey of approximately 6,000 young men and 6,000 young women between the ages of 14 and 21. These young people have been followed up every year up to the present. In 1986, the NLSY began assessing the children of the female NLSY respondents at two year intervals. Given the differences in the design of the two studies, and the large amounts of missing data in the NLSY, we use the NLSY data to see how the average

effect on schooling attainment. Cuellar, Markowitz, and Libby (2003) show that adolescents in the Colorado state foster care program who received treatment for their mental health problems were less likely to engage in crime.

${ }^{9}$ Of the 9,542 children eligible to receive the tests, 86 percent of parents consented to have the school board administer the tests and 97 percent of school boards consented to conduct the tests. However, due to administrative problems, only 65 percent of the administered tests were returned to Statistics Canada in 1998. Therefore, of the original 9,542 children eligible to take the test, we have test scores for only 5,153 children (this number represents all children in the sample, including those outside the age range we investigate). The response rate for 1996 was significantly higher (closer to 75 percent). Using the 1996 test scores rather than the 1998 test scores yields results that are qualitatively similar to those reported below. Statistics Canada has conducted an analysis of the non-response, and finds that there is very little difference between responders and non-responders along observable dimensions (such as gender, type of school, whether the children had ever repeated a grade, or the 
hyperactivity score measured over the 1990 to 1994 period affects the average outcomes of children in the 1998 and 2000 waves. This procedure yields a maximum sample of 5,348 children. We restrict the age range of the NLSY children to be greater than 4 and less than 12 years of age in 1994 to make the Canadian and U.S. samples more comparable. ${ }^{10}$

The NLSCY offers a number of advantages over the NLSY for our analysis. First, the NLSCY began with a nationally representative sample of children in 1994. In contrast, the mothers of the NLSY children represented a nationally representative cohort of 14 to 21 year old women in 1978. Since women of lower socioeconomic status tend to have children at younger ages, the NLSY sample of children is disadvantaged relative to a nationally representative cross section of children, although this is a less of a problem after we have deleted the oldest children. Second, the NLSCY has better measures of physical health than the NLSY, as discussed further below. Third, the NLSCY has both parent and teacher reports of ADHD, a feature that we exploit in our analysis. An advantage of the NLSY is that we can identify children who have been diagnosed with ADHD which allows us to compare estimates based on diagnosed cases to those based on the screener. However, as we will show below, the estimates are remarkably similar in the U.S. and Canada despite differences in sampling and design, which lends strength to our conclusions regarding the importance of ADHD. We have also re-estimated all of our models using sample weights, and this did not affect our results.

importance that the parent respondent attaches to education).

${ }^{10}$ Focusing on 4-11 year olds also improves our ability to compare across outcome measures in the NLSY. The reason is that test scores are available only for children aged 5 to 14 , while measures of delinquency are available for much older children. Estimating our models for the full available sample for each outcome measure in the NLSY yielded estimates qualitatively similar to those discussed below. The main exception is that the interaction between income and hyperactivity scores is positive in OLS using the full U.S. sample. In other words, in the sample of older NLSY children, there IS a positive relationship between income and probability of treatment conditional on hyperactivity scores. 
The measurement of ADHD is key for our analysis. The measures available in our surveys, as in most surveys, are questions that are asked to parents and/or teachers about symptoms of ADHD. We do not have information whether the symptoms are causing impairments, but given the way that ADHD is diagnosed, it is obvious that children who are having problems in school are more likely to be judged to be "impaired" by their symptoms in the school setting than those who are not. Hence, whatever the underlying symptoms, there is likely to be a spurious relationship between schooling achievement and diagnosed ADHD. As we will show below using U.S. data, diagnosis generally implies placement in special education. Given this relationship, as well as concerns about the extent to which ADHD is either over or under-diagnosed, we focus on the extent to which children exhibit symptoms, rather than on whether or not children have been diagnosed with ADHD. ${ }^{11}$

ADHD is always diagnosed through the use of questions similar to those included in both surveys. In the NLSCY data, the teachers and parents of all children aged 4 through 11 in 1994 were asked a series of 8 questions (we list the questions in the data appendix). The responses to these questions were added together to determine a hyperactivity score for the child. Since the hyperactivity score is generated from a set of questions asked of all respondents, our measure captures a set of ADHD symptoms and is not dependent on whether the child has been diagnosed with ADHD. This avoids criticisms of mental health measures based on the set of children who seek treatment for their illness (Frank and Gertler, 1991).

The NLSY Behavior Problems Index is asked to parents of children 4 to 14 . There are 26 questions asked to all children, and 2 questions asked only to children who have been to school.

\footnotetext{
${ }^{11}$ Most of the literature focuses on children who have been diagnosed with ADHD. However, Merrell and Tymms (2001) show that symptomatic children who have not been diagnosed suffer from similar problems.
} 
Five of the questions can be used to create a hyperactivity subscale. This score is standardized by the child's sex and age. We convert this standardized score to one that has the same range as the score in the Canadian data. More information about how these scores are computed in both samples is available in the data appendix.

In the NLSY, parents were also asked whether their children had any conditions that limited their normal activities. If they answered in the affirmative, parents were asked to identify the limitation. We code children as having been diagnosed with ADHD if the parent identifies any of the following conditions: "Minimal brain dysfunction, minimal cerebral dysfunction, attention deficit disorder", or "Hyperkineses, hyperactivity". Minimal brain dysfunction is a term that was used to describe ADHD when the leading theory was that the disorder was caused by brain damage in infancy. The same suite of questions was used to identify children who had been diagnosed with a "learning disability". In the Canadian NLSCY we use a question on whether the child has been diagnosed with a learning disability that is asked in the series of questions on chronic conditions. Below, we examine the effects of ADHD symptoms in a sample of children that excludes those with diagnosed learning disabilities, in an effort to isolate the effects of ADHD itself.

We focus on a set of outcomes that are intended to capture the child's human capital accumulation, broadly defined. These include: Grade repetition, mathematics scores, reading scores, and special education. Since ADHD is often thought of as a primarily behavioural affliction, we also look at delinquency, which may be more closely related to the child's behaviour problems. Further details about the construction of these variables are available in the data appendix, but some general discussion is warranted here. 
Grade repetition is an important outcome, in that it is predictive of eventual schooling attainment. Since whether or not someone has ever repeated a grade is a cumulative measure, we ask whether the child repeated a grade between 1994 (when hyperactivity is measured) and 1998 (2000 in the NLSY). Mathematics and reading scores are two more immediate measures of schooling achievement. The NLSY assesses children using the Peabody Individual Achievement Tests (PIATs) for mathematics and reading recognition. These tests are administered in the home. In the NLSCY, mathematics and reading tests were administered in schools to children in grades two through ten and are based on the Canadian Achievement Tests.

The special education variable in the NLSY, corresponds to a parental report that the child was in a special education class in 2000. In the NLSCY, the teacher is asked whether the child received special education because of a physical, emotional, and behavioural or other problem that limited their ability to do school work. We count only students who received special education because of a mental health condition. Although this might appear to be a more restrictive protocol than in the U.S., the prevalence of positive responses is actually higher in Canada than in the U.S. Special education is an important variable to consider, because special education children tend to lag behind their peers throughout their schooling and are more likely to drop out.

The measure of delinquency that we construct using NLSY data corresponds closely to that used by the U.S. Department of Justice (DIJ) for this age group. The DIJ definition includes illegal drug use or sales, “destroyed property”, “stolen something worth more than $\$ 50 ”$, “committed assault”, and whether they have ever been arrested (Puzzanchera, 2000). The NLSCY measure is slightly broader in that it also includes questions about whether children have 
been questioned by police, or have run away from home. Questions about drug use and delinquency are answered by the child in both surveys.

While the Canadian survey has very good physical health information, the health information in the NLSY is limited, and difficult to use. For example, in the NLSY, questions about chronic conditions are asked only about children who have an activity limitation, and the "poor health" question is not asked in all waves of the survey. Hence, we limit our comparison of ADHD with physical health problems to the Canadian data. In the NLSCY, the respondent is asked to rate the health of the child on a scale of 1 to 5 , with 1 being poor and 5 being excellent. We define poor health as the bottom three measures on this scale ${ }^{12}$. Information is also collected on chronic conditions (these include allergies, asthma, heart disease, bronchitis, epilepsy, cerebral palsy, kidney troubles, and a category for other chronic conditions) for all children. ${ }^{13}$ We excluded learning disabilities, and psychological disabilities from this list of chronic conditions in order to focus on physical health problems.

We use total permanent household income as our measure of income. This variable is constructed by taking the mean income for all available waves. ${ }^{14}$ We average income over all waves for two reasons. First, child outcomes are likely to be more strongly affected by permanent than by transitory income. Second, the impact of random measurement error in the

\footnotetext{
${ }^{12}$ In this case "poor health" combines poor, average, and good health. We choose to include responses of good health in our "poor health" measure as only small fraction of parents rate their child's health in the bottom three categories a the 5 point scale.

${ }^{13}$ It is possible that a parent might classify a child with mental health problems but no physical health problems as in poor health. However, the correlation between the teacher-reported hyperactivity score and the poor health measure was only .09, suggesting that in general parents do not consider ADHD when answering questions about health status.

${ }^{14}$ In the NLSY, we use all income measures from 1990 onwards.
} 
OLS estimates also will be attenuated by averaging. ${ }^{15}$ While it would be preferable to have past income (prior to 1994) included in this calculation as well, the first year of the NLSCY is 1994.

Means of all of our measures are shown for all children with non-missing hyperactivity scores are shown in columns 1 and 4 of Table 1 . Columns 2 and 5 show means for the sample of children with siblings, who will be the focus in our fixed effects models. In the NLSY, all siblings in sampled households are interviewed, whereas in the NLSCY, one randomly chosen sibling is interviewed. Columns 3 and 6 show the number of siblings with a within-family difference in the variable in question, since these are the children who will identify the effects of hyperactivity in our models.

This table suggests that the sibling sample is quite similar to the "full" sample of children, and that there are sufficient numbers of siblings with differences in outcomes to pursue a fixed effects strategy for most of our outcomes. The mean difference in hyperactivity scores, where there is a difference, is 3.96 in Canada and 3.07 in the U.S, which is roughly a one standard deviation difference. Table 1 also shows that the mean difference in hyperactivity scores between boys and girls is relatively small (slightly larger in Canada than the US), while there is a much greater gender difference in the probability of being above the $90^{\text {th }}$ percentile of the score distribution.

The U.S. sample also has information about diagnosed cases of ADHD. Table 1 indicates that only about $2.6 \%$ of children had such a diagnosis in 1994 . This is about the same fraction that has been diagnosed with "learning disabilities" and there is significant overlap in the

\footnotetext{
${ }^{15}$ In cases where the household income is not reported, the NLSCY imputes it. We include a dummy variable for the imputation of household income in all of our analyses. We also re-estimated all our analyses omitting individuals for whom income had been imputed in order to be sure that there was nothing peculiar about the income imputation process. Our analyses are robust to these checks.
} 
two samples: Of the 96 children with diagnosed ADHD, 40 have other learning disabilities. We can also examine the screener score measure for children diagnosed with ADHD. In this group, only $35 \%$ have a score higher than the $90^{\text {th }}$ percentile of the ADHD score distribution. These comparisons highlight difficulties with using ADHD diagnosis as a measure. On the one hand, it appears that ADHD is under-diagnosed in this population, since $2.6 \%$ is much less than the $4-5 \%$ estimated prevalence. On the other hand, many of the children diagnosed with ADHD appear to have few behavioural symptoms (even when they are not being treated), suggesting that they have perhaps been erroneously diagnosed, or that there is potentially measurement error in the reporting of symptoms in the survey.

The table highlights similarities and differences between the U.S. and Canadian samples. The U.S. children are slightly older and born to somewhat younger mothers on average, as one would expect. They are also more likely to have mothers who are depressed or have an activity limitation. All of these differences as well as differences in other observable variables in the two data sets are controlled for in our Ordinary Least Squares (OLS) models, and many of them will be absorbed by family fixed effects in the fixed effects models. The U.S. children are much more likely to be delinquent, and twice as likely to repeat grades. However, they are slightly less likely to be in special education. ${ }^{16}$

Both the NLSY and the NLSCY have information about drug and psychiatric treatment for mental health conditions, as shown in Table 1. In 1994, only 1.4 percent of the Canadian children reported drug treatment compared to 3.3 percent of the American children. The NLSCY

\footnotetext{
${ }^{16}$ In the U.S., the scores are standardized using national norms for children of the same sex and age. Such norms are not available for these Canadian tests. However, we control for the child's sex and age in our regressions. The Canadian math and reading scores are out of 15 and 20 respectively. For ease of comparison with the U.S.
} 
asks specifically about Ritalin, tranquillizers and nerve pills, whereas the NLSY asks a more general question about medications used to control activity levels or behavior. ${ }^{17}$ The Canadian children were also less likely to have seen a psychiatrist, resulting in overall treatment rates of 4.7 percent compared to 9.6 percent for the American children.

These differences in mean rates of treatment are surprising in view of differences in the insurance regimes in the two countries: In Canada, psychiatric treatment is covered under public health insurance, and all of the provinces have drug plans for low-income families. In the U.S., many private insurance plans severely restrict the coverage of mental health treatment, and Medicaid (the public system of health insurance for low income children) offers only limited coverage of psychiatric treatment. The low treatment rates in Canada may reflect greater stigma attached to mental illness, less faith in the efficacy of treatment, or both.

A comparison of the distribution of NLSCY teacher reports, NLSCY parent reports, and NLSY parent reports of hyperactivity is shown in Table 1b. The first two columns suggest that the teacher and parent reports do contain independent information-in Canada parents are much more likely to report low levels of symptoms than teachers and the correlation between the two scores is only .46. Half of the children receive scores of two or less from teachers, while the median parent score is 4 .

results, we have multiplied the Canadian math and reading scores by 6.67 and by 5 in the means tables. We multiply coefficients and standard errors by the same factors in all the subsequent tables as well.

${ }^{17}$ In comparison, the Centre for Addiction and Mental Health in Ontario, which conducts a student drug use survey in 2001, found 4.2 percent of seventh and eighth graders in Ontario reported using Ritalin within the past 12 months (Adlaf and Paglia, 2001). However, in the NLSCY reported use of Ritalin has increased significantly since 1994. For example, among 10 year olds the incidence of Ritalin use increased from 2.5 to $4.1 \%$, while among 11 year olds, it increased from 1.3 to 3.9\% between 1994 and 1998. 
The U.S. distribution indicates lower fractions of children with very low scores, and higher numbers of children with high scores since the median score is 6 . The $90^{\text {th }}$ percentile score is also somewhat higher in the U.S. distribution. Scores exceeding 8 have been shown in previous research to be associated (though imperfectly) with diagnosed ADHD (Baillargeon et al, 1999). In our Canadian data, a cutoff of 9 yields prevalence rates of about 14 percent which corresponds with Willms (2002) finding that approximately 14 percent of children in the NLSCY are hyperactive. ${ }^{18}$ But since 14 percent is much higher than the 4-5 percent estimated prevalence of ADHD in the U.S., we have chosen to compromise and focus on the $90^{\text {th }}$ percentile score for both the U.S. and Canada.

Table 1c shows that there are large mean differences in outcomes between children above and below the $90^{\text {th }}$ percentile of the hyperactivity score. In the US, high scores double the risk of grade repetition and special education, and are associated with a half of a standard deviation reduction in reading and mathematics scores. The difference in the probability of delinquency is more modest, which is perhaps surprising given that ADHD is thought of as a primarily behavioral disorder. In Canada, the differences in outcomes between children with high and low scores are perhaps even starker than in the US, with a rate of grade repetition that is more than three times higher, and a rate of special education that is more than 5 times higher.

An important question is whether we expect the effect of hyperactivity symptoms to be roughly linear, or whether scores above some threshold have much more deleterious effects? People often think about illness in terms of thresholds—only people with blood pressure above a set cut off are diagnosed with high blood pressure, and only people whose insulin function is

\footnotetext{
${ }^{18}$ In a survey of students in three Ontario school districts, Sgro et al. (2000) use a cutoff of 9 or higher as a "diagnosis" of ADHD and find rates around 5 percent. Since response rates to the survey instrument used in Sgro et al, were less than 29 percent, it is likely that the NLSCY numbers are more accurate.
} 
subject to a certain degree of impairment are diagnosed with diabetes. However, in both of these examples, recent research has shown that persons with readings below the relevant thresholds for diagnosis still suffer from negative effects. This could also be the case with ADHD symptoms.

Figure 1 shows non-parametric Lowess plots of outcomes against hyperactivity scores for the U.S. and Canada. There are two striking things about these pictures. First, they are remarkably similar for the U.S. and Canada despite differences in samples, educational systems, variable definitions and so on. Second, all of the outcomes except delinquency change approximately linearly with hyperactivity scores. This observation suggests that even children with scores low enough that they would never be diagnosed with ADHD, may nevertheless suffer ill effects of behaviours associated with the syndrome. Hence we look at the effect of linear ADHD scores as well as the $90^{\text {th }}$ percentile.

The negative effects of ADHD on delinquency top out at around the $90^{\text {th }}$ percentile of both the U.S. and Canadian distributions. We have estimated models with splines at the $90^{\text {th }}$ percentile in order to take account of the effect of this non-linearity, but did not find that our results were materially affected, so these results are not reported below.

\section{Methods}

We begin by estimating OLS models of the relationship between hyperactivity scores in 1994 and outcomes in 1998, controlling for a wide range of other potentially confounding variables, including permanent income; maternal health status, education and family structure (in 1994); child age (single year of age dummies), whether the child is first born, and sex.

These models have the following form: 


$$
\text { (1) outcome98 }_{i}=\alpha+\beta \text { ADHD94 }_{i}+\lambda X 94_{i}+\varepsilon_{i}
$$

where outcome98 is one of the outcomes described above, ADHD94 is the child's hyperactivity score (either the continuous score or a cut-off for a score above the $90^{\text {th }}$ percentile) and $X$ is the vector of covariates described above. If high hyperactivity scores are positively correlated with other factors that have a negative effect on child outcomes, then these estimates will overstate the true effect of hyperactivity.

We next attempt to control for unobserved heterogeneity by estimating family fixed effects models:

$$
\text { (2)outcome98 }_{\text {if }}=\alpha+\beta A D H D 94_{\text {if }}+\lambda Z 94_{\text {if }}+\mu_{f}+\varepsilon_{\text {if }}
$$

In these models, the $\mathrm{Z}$ vector is similar to $\mathrm{X}$ but omits factors common to both siblings, and the $f$ subscript indexes families. A comparison of (1) and (2) will indicate whether OLS estimates are driven by omitted variables at the family level. Evidently, there may be individuallevel factors that are important and which will not be captured by family fixed effects. However, it is impractical to estimate models with child fixed effects because ADHD is a symptom that typically emerges before the child's $7^{\text {th }}$ birthday. Thus, changes in ADHD scores over time for the same child are likely to reflect measurement error, rather than true changes in mental health status. One of the most important individual-level factors is likely to be whether the child has other learning disabilities. We deal with this problem by re-estimating models excluding children with other diagnosed learning disabilities below.

If a high hyperactivity score for one sibling has negative effects on the achievement of other siblings in the household, then the difference between the two siblings will provide an under-estimate of the effects of hyperactivity. Estimates of (2) may also be biased downwards by random measurement error in the hyperactivity scores. Measurement error is a potentially 
important problem in this and all of the past studies relying on parental reports of children's mental health disorders (c.f. Offord et al., 1988; Garrett, 1996; Glied et al, 1997).

One way to judge the importance of measurement error is to compare the OLS and fixed effects estimates. If we believe that part of the true effect of ADHD is persistent between siblings, then the within family variation may be more "noisy" than the between family variation. In this case we might expect increased attenuation bias in the fixed effects estimates. However, as we show below, these estimates are very similar suggesting that in practice, measurement error (or potential spillover effects, as noted above) may not be such an important problem. In the Canadian data, we also adopt a second approach to measurement error which uses the fact that this survey independently asks identical questions about the mental health of the child of both teachers and parents. Specifically, we estimate models using parent reports as instruments for teacher reports in order to correct for measurement error. The identifying assumptions are first, that conditional on the teacher report and on the family fixed effect included in the model, the parent report has no independent effect on the child's test scores and other outcomes. Second, while we assume that the "signals" in the parent and teacher reports are correlated, the instrumental variables estimates are only consistent if the errors in the parent and teacher reports are uncorrelated.

Given that the questions are asked independently and that they concern very specific observed behaviors, we believe this second assumption is reasonable. For example, suppose that the teacher and the parent had discussed the fact that the child might have ADHD. There is no reason why this would cause correlated errors in the responses to a set of questions about specific behaviors that are not linked to ADHD in any way in the questionnaire. 
A third potential problem is that a small number of children in our samples are being treated for ADHD. Treatment for ADHD generally consists of drug treatment (with stimulants such as methylphenidate or amphetamine), psychiatric counseling for parents and children aimed at behavioral modification, or both. Drug therapy is effective in improving behavior for approximately 70 to 80 percent of children. However, Swanson et al. (1991) indicate that there is little evidence that drug treatment consistently improves cognitive performance on academic tasks in a laboratory setting. ${ }^{19}$

To the extent that treatment is effective in altering behavior, children who are being treated will have lower ADHD scores than they otherwise would have, since the questions used in the screener focus on behavior. But if treatment has no consistent impact on cognitive outcomes such as test scores (as Swanson’s research suggests) then failing to account for treatment will bias our estimates. For example, if all ADHD children were treated, it might appear that even low ADHD scores were associated with significantly poorer outcomes, and our results would be biased upwards.

It would be extremely interesting to be able to conduct our own analysis of the impact of treatment on outcomes. However, the very small number of children who are treated (especially in Canada) and the endogenous nature of treatment decisions (along with the lack of plausible instruments for treatment) make this difficult. Instead, we take two alternative approaches to the problem of treated children. First, we simply exclude the treated children. If treatment were applied randomly to the population of children, then these estimates would provide an unbiased

19 They point to two reasons for mixed results of drug therapy. First, drug doses that are too high may impair cognitive functioning. For simple tasks, the performance of ADHD children improves linearly with dose, while for tasks that require mental effort, performance improves at low doses and then declines. Thus, they conclude that the doses administered to control behavior may be higher than optimal for improving academic performance. Second, there are children whose performance on cognitive tests does not improve with drug therapy 
estimate of the effects of untreated ADHD scores on outcomes. Second, we impute the $90^{\text {th }}$ percentile score to all of the treated children. This is equivalent to assuming that only children with high scores are treated. As we will show, neither alternative has much impact on our estimates, given the small numbers of children being treated.

We also examine gender differences in the effects of ADHD. As Table 1 shows, on average, boys score only slightly higher on the ADHD index than girls, but are much more likely to be above the $90^{\text {th }}$ percentile of the distribution. We ask whether similar levels of ADHD scores affect boys and girls similarly by interacting the dummy variable for "male" with the hyperactivity score in models of the form (2).

Finally, we turn to an investigation of the extent to which the effects of ADHD are mediated by income. The OLS models we estimate have the following form:

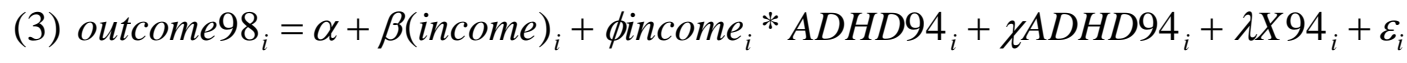
where now income has been broken out of the $\mathrm{X}$ vector, and interacted with the hyperactivity score. A positive coefficient on the interaction term (in the case of a positive outcome) would suggest that the negative effects of ADHD were mitigated in high income children. If it were the case that high income children with ADHD were more likely to be treated than other children, and had either better or worse outcomes than lower income children, then models of this type would provide some evidence (albeit indirect) about the efficacy of treatment. Hence, we also estimate models of treatment probabilities that take the form (3). However, we show below that neither outcomes nor treatment probabilities vary much with income (in contrast to the strong relationship between income and treatment (or quality of treatment) that holds for most physical

at all, and may even be impaired. Some studies suggest that up to 40 percent of children treated with stimulant drugs do not have any favorable cognitive response. 
illnesses). While these results are interesting in and of themselves, they make it difficult to infer anything about the effectiveness of treatment from our estimates.

\section{Results}

Table 2 presents our baseline OLS estimates of the effects of hyperactivity on child outcomes in the U.S. and Canada. Table 2 indicates that children with higher hyperactivity scores have outcomes that are worse in all of the measured dimensions. The estimated effects of a one unit change in the hyperactivity score are generally somewhat lower for the U.S. than for Canada, though for reading scores, they are somewhat larger.

One way to think about the size of these effects is to compare them with the effect of income, which has consistently significant effects, and generally has larger effects in the U.S. than in Canada. For example, in Canada, each $\$ 100,000$ worth of permanent income is associated with a 3.8 percentage point decrease in the probability that a child repeats a grade between 1994 and 1998. But a Canadian child with a score of only 5 out of 16 on the hyperactivity index would be 3.5 percentage points more likely to have repeated a grade. Thus, in Canada, the effect of hyperactivity is large relative to the effect of income. The same comparison in the U.S. data suggests that each $\$ 100,000$ increase in permanent income would decrease the probability of grade repetition by 5.3 percentage points, compared to a 2 percentage point increase in the probability for a child with a hyperactivity score of 5 relative to a child with a hyperactivity score of zero.

Having a mother with at least a high school education is also consistently related to positive outcomes, especially in the U.S., with the effect being generally similar to that of $\$ 100,000$ worth of income. Other variables with consistently significant effects are the indicator 
for Hispanic ethnicity, which has negative effects (in the NLSY data only; Race and ethnicity are not available in the NLSCY), and having two parents in 1994, which has positive effects in the NLSY data, though in Canada it is only statistically significant in the model of delinquency. Males are more likely to be delinquent, more likely to repeat grades, and (in the U.S.) more likely to be in special education, consistent with other studies.

The robustness of these effects is investigated further in Table 3. The first panel of Table 3 repeats the OLS estimates of the effects of hyperactivity and income from Table 2 . The second panel presents fixed effects estimates. Except for delinquency, these within-family estimates are very similar to those in Panel 1, indicating that the OLS results for academic outcomes are not driven by unobserved heterogeneity between families (though OLS estimates for delinquency may be). The similarity between the OLS and fixed effects estimates suggests that measurement error is not driving the estimates, as discussed above. ${ }^{20}$

Panel 3 of Table 3 focuses on the children with the highest ADHD symptom scores by using a dummy variable for scores above the $90^{\text {th }}$ percentile rather than the continuous hyperactivity score as the independent variable of interest. Having a high hyperactivity score has no effect on delinquency in models with fixed effects, but does affect all of the other outcomes. The coefficient estimates are consistent with roughly linear effects on grade repetition and special education, while the estimated effects on test scores are substantial but somewhat smaller than one would project on the basis of the linear models.

\footnotetext{
${ }^{20}$ Random measurement error would be expected to reduce the size of the fixed effects estimates relative to the OLS estimates. Correlated errors (for example, if the mother tended to consistently exaggerate reports of a particular behavior for both children) would lead to much larger fixed effects estimates. If, on the other hand, parents exaggerate differences between siblings, the fixed effects estimates could theoretically be smaller than the OLS estimates.
} 
If high ADHD scores are correlated with having learning disabilities, or other conditions that may impair outcomes, then we may be attributing part of the effect of other disabilities to our ADHD measure, thereby overestimating the true effect of ADHD on outcomes. In the U.S., $8 \%$ of children with an ADHD score above the $90^{\text {th }}$ percentile are also diagnosed with a learning disability, and in Canada, the comparable figure is $10 \%$. We address this potential problem by estimating the effects of ADHD in a sample that excludes children with diagnosed learning disabilities. Panel 4 of Table 3 shows that excluding these children has little impact on our estimates.

We have also estimated models excluding children in special education from our samples. The rationale for this experiment is that since children with ADHD are more likely to end up in special education, the estimated effects of ADHD might be contaminated by the effects of being in this track. However, our estimates (not shown) were very similar to those shown in Panel 2.

Panel 5 of Table 3 shows estimates for the sample of children who were age 4 to 7 in 1994. As discussed above, in order for a diagnosis of ADHD to take place, symptoms must have appeared before age 7. Among older children behavior problems that mimic ADHD might appear in response to school-related difficulties. This restriction dramatically reduces our sample sizes, particularly for the Canadian test scores. However, the U.S. estimates are very similar to those reported in Panel 2, and the Canadian estimates of the effects of ADHD symptoms on grade repetition and special education are also similar for grade repetition and special education (we lose statistical significance in the Canadian test score models, but this may be because of the large reduction in sample size for these outcomes). 
Panel 6 of Table 3 shows that if teacher-reported scores are instrumented with parent reports in the Canadian data, the fixed effects-IV estimates are similar to the OLS estimates for grade repetition and math scores and much higher than the fixed effects (or OLS) estimates for special education (F-statistics for our first-stage are reported in the notes to the table). We take the estimates for special education with a grain of salt, as it may be the case that parent reports about the child's behavior do have an independent effect on the probability that the child is placed in special education after the teacher's report is accounted for. We believe that this is less likely to be the case with test scores.

Panel 7 uses the measure of diagnosed ADHD rather than the screener measure. Comparing these estimates with those in Panels 2 and 3 suggests that focusing on diagnosed cases greatly exaggerates the extent to which ADHD symptoms per se lead to special education. On the other hand, the extent to which ADHD symptoms are related to grade repetition is understated if we use only diagnosed cases. These two phenomena may be related if children are less likely to be retained in grade once they have been placed in special education, and if diagnosis with ADHD is often an entrée into special education.

It is interesting that judging by the point estimates, both being diagnosed, and having a score above the $90^{\text {th }}$ percentile have very similar negative effects on reading scores, although only the estimates using the score measure are statistically significant because of large standard errors in the models using diagnosed cases. Again, this result suggests that there may be a good deal of measurement error in diagnosed cases. For math scores, being diagnosed has a larger negative effect than scoring highly on the screener, but both are imprecisely estimated.

Table 4 shows models that either exclude treated children, or impute a high hyperactivity score to these children. For the most part, these alternative ways of handling the treated children 
produce estimates that are very similar to those shown in Table 3 . The main exception is that the hyperactivity score does not have a significant effect on the probability of special education in the U.S. in these models. This result suggests once again that it is the treated children in the U.S. who end up in special education, and that untreated children with the same ADHD scores as the treated children are not more likely to end up in special education.

Table 5 asks whether effects differ for boys and girls. When we consider the linear score measure, it appears that girls suffer as much as boys from the symptoms of ADHD—none of the interaction terms are statistically significant (though most of the ADHD main effects are also insignificant). But when we use the dummy for the $90^{\text {th }}$ percentile of the hyperactivity distribution, interesting gender differences emerge. In particular, in both Canada and the U.S., only hyperactive boys appear to be at risk for being placed in special education. And in the U.S., the negative effects of high hyperactivity scores on reading and math scores is confined to boys.

Table 6 offers an alternative way to think about the magnitude of these effects. In it, we compare the estimated effect of hyperactivity to the effects of physical health problems, using the Canadian data. Table 6 shows that in fixed effects models, neither having been diagnosed with a chronic health problem such as asthma (the most common chronic physical condition among children) as of 1994, nor a maternal report that a child is in poor health in 1994 is predictive of poorer outcomes as of $1998 .^{21}$ These results suggest that on average ADHD has a greater impact on academic achievement than serious physical health problems.

21 In OLS models, chronic conditions in 1994 have no effect on future outcomes but a maternal report that a child is in poor health is predictive of poorer outcomes in 1998. We cannot be certain that mothers answer this question with only their child's physical health in mind, but the correlation between being in poor health and the hyperactivity score is very small (0.09). In OLS models, a moderate hyperactivity score generally has worse effects than being in poor health. For example, among Canadian children, being in poor health in 1994 is associated with a reduction of .43 in 1998 mathematics scores, while a score of 5 out of 16 on the hyperactivity index is associated with reduction of 1.3 (on a mean score of 8.1). 
Table 7 reports estimates of equation (3), which include interactions between hyperactivity scores and income. Panel 1 shows that in OLS models using the NLSY, the interactions are of the expected sign (that is, higher income appears to mitigate the effects of hyperactivity) but none of them are statistically significant. In contrast, in Canada all of the interactions are significant in the OLS models, except in the model of delinquency. Panel 2 shows, however, that once we control for heterogeneity between families, only the interaction term that remains statistically significant is for grade repetition in Canada.

Given that we are using permanent income, the interaction terms in these fixed effects models are identified by the fact that ADHD scores vary within families. What the interaction term tells us is whether the difference between the high and low ADHD score children within a family is bigger in a low income household than in a high income household. That is, if the high income household is able to do a better job assisting the high ADHD score child than the low income household, then the interaction will be significant.

Panel 3 of Table 7 indicates that the interaction of income and having a hyperactivity score above the $90^{\text {th }}$ percentile is associated with a higher probability of grade repetition in both the U.S. and Canada, and the point estimates in the two countries are quite similar (although the U.S. coefficient is significant only at the 90 percent level of confidence). However, the other interaction terms remain statistically insignificant. In summary then, within families with children with differing levels of hyperactivity, being in a higher income family offers little protection against the negative effects of ADHD on test scores, although the high ADHD child in the high income family is less likely repeat grades than a similar child in a low income family. 
Table 8 investigates the relationship between hyperactivity scores, income, and treatment. OLS estimates indicate that income has no effect on the probability of treatment in either the U.S. or Canada. This is a surprising result, particularly in the U.S. where richer children generally have better access to medical care. The main effects of income are insignificant as well, except that in the U.S., children from wealthier families are more likely to see a psychiatrist. In the U.S., maternal education also increases the probability of treatment as does having a mother who is depressed or has an activity limitation. Children of younger mothers and Hispanic children are much less likely to be treated, as are children in two parent families.

The second panel of Table 8 presents fixed-effects estimates. In order to interpret our fixed effects models it may be useful to consider an example. Consider two families, one with high income and the other with low income. Each family has two children, one with a high ADHD score, and one with a low ADHD score. The question posed by the interactive models is: Is the child with the high score more likely to be treated in a high income family? The answer is no -- in these models, the only interaction that is statistically significant suggests that conditional on their hyperactivity score, richer Canadian children are actually less likely to see a psychiatrist than other children.

It is useful to think about the estimation biases that the effects of treatment of ADHD might create. Suppose for example, that high income children really were more likely to be treated, and that treatment lowered their hyperactivity scores. Then we would see high income children with relatively low scores being treated, suggesting that conditional on their score, high income children were even more likely than low income children to be treated. This argument suggests that if anything the estimates in Table 8 over-estimate the true interaction between 
income and ADHD scores, suggesting that there really is a very weak effect of ADHD scores on the probability of being treated.

\section{Discussion and Conclusions}

Children with symptoms of hyperactivity suffer large negative consequences in terms of their achievement test scores and schooling attainment. Hyperactivity is a more important determinant of reduced human capital accumulation than physical health problems. These results are qualitatively similar in the U.S. and Canada and are robust to many changes in specification.

We also find that a given level of symptoms has similar effects on the test scores of rich and poor children although richer children are less likely to be retained in grade, which may be a significant advantage. Boys and girls with moderate levels of symptoms also suffer equally in terms of academic outcomes, though boys with high hyperactivity scores do worse than girls, especially in the U.S..

A silver lining is that there is no evidence that poor children suffer from "double jeopardy”. Even if we assume that treatment is effective, there is surprisingly little relationship between income and treatment probabilities in these data. The lack of a strong relationship between income and drug treatment for ADHD contrasts sharply with a large literature showing that richer children are more likely to be treated for physical health problems, conditional on the need for such treatment.

It is interesting to speculate on why rich parents appear to be relatively less likely to seek treatment for ADHD than for other ailments. One reason may be that a diagnosis of ADHD is strongly related to placement in special education, and wealthier parents may wish to avoid this 
outcome. At the same time, drug treatment for ADHD has become more commonly available to low income children through Medicaid and schools may face strong incentives to have lowachieving children diagnosed and treated for ADHD so that they can be placed in special education (Cullen, 2003).

Finally, we find that even children whose relatively low level of symptoms make them unlikely candidates for diagnosis will suffer significant ill effects. The severity of the problems associated with ADHD and the pervasiveness of its symptoms suggest that efforts to find better ways to teach the relatively small number of children diagnosed with ADHD could have a large payoff in terms of improving the academic outcomes of many children with milder symptoms. 


\section{References}

Adlaf, E., Paglia, A., “Drug Use Among Ontario Students 1977-2001,” Centre for Addiction and Mental Health Research Document Series, No. 10, 2001.

American Academy of Pediatrics. "Diagnosis and Evaluation of the Child with AttentionDeficity/Hyperactivity Disorder, Practice Guidline,” Pediatrics, 105 \#5, May 2000, 1158-1170.

American Psychiatric Association. Diagnostic and Statistical Manual of Mental Disorders, 4th Ed. 1994.

Baillargeon, R., Tremblay, R., Willms, J.D., “The Prevalence of Physical Aggression in Canadian Children: A Multi-Group Latent Class Analysis of Data from the First Collection Cycle (1994-1995) of the NLSCY,” Human Resources Development Canada, Applied Research Branch, December 1999.

Cuffe, Steven, Charity Moore, and Robert McKeown. "ADHD Symptoms in the National Health Inverview Survey: Prevalence, Correlates, and the Use of Services and Medication,” poster presented at the $50^{\text {th }}$ Anniversary Meeting of the American Academy of Child and Adolescent Psychiatry, Miami Beach FL, October 15, 2003.

Caspi, Avshalom, Bradley Wright, Terrie Moffitt, and Phil Silva. "Early Failure in the Labor Market: Childhood and Adolescent Predictors of Unemployment in the Transition to Adulthood,” American Sociological Review, 63, 1998, 424-451.

Cuellar, Alison, Sara Markowitz, Anne Libby. "The Relationships Between Mental Health and Substance Abuse Treatment and Juvenile Crime,” NBER Working Paper \#9952, Sept. 2003.

Currie, Janet. "Health Disparities and Gaps in School Readiness” in The Future of Children: School Readiness: Closing Racial and Ethnic Gaps, Volume 15, Number 1 - Spring 2005, 117138.

Currie, Janet and Brigitte Madrian. "Health, Health Insurance and the Labor Market", The Handbook of Labor Economics, volume 3c, David Card and Orley Ashenfelter (eds.) (Amsterdam: North Holland), 1999, 3309-3407.

Dooley, Martin, and Stewart, J. "Family Income, Parenting Styles and Child BehaviouralEmotional Outcomes,” mimeo, McMaster University, 2003.

Dooley, Martin, Curtis, Lori, Lipman, Ellen, and Feeny, David, "Child Psychiatric Disorders, Poor School Performance and Social Problems: The Roles of Family Structure and LowIncome," in Labour Markets, Social Institutions, and the Future of Canada's Children, ed. M. Corak, 1998, Statistics Canada: Ottawa, Canada. 
Ettner, S., Frank, R., Kessler, R., “The Impact of Psychiatric Disorders on Labour Market Outcomes,” Industrial and Labor Relations Review, 1997, 51(1), pp.64-81.

Farmer, Elizabeth. "Externalizing Behavior in the Life Course: The Transition from School to Work,” Journal of Emotional and Behavioral Disorders, 1, 1993, 179-188.

Farmer, Elizabeth. "Extremity of Externalizing Behavior and Young Adult Outcomes,” Journal of Child Psychology and Psychiatry, 36, 1995, 617-632.

Fiore, Thomas, Elizabeth Becker, and Rebecca Nero. "Educational Interventions for Students with Attention Deficit Disorder,” Exceptional Children, 60 \#2, 1993, 163-173.

Frank, R., Gertler, P., “An Assessment of Measurement Error Bias for Estimating the Effect of Mental Distress on Income,” The Journal of Human Resources, 1991, 26(1), pp.154-164.

Garrett, A.B., Essays in the Economics of Child Mental Health, Columbia University Ph.D. Thesis, 1996.

Glied, S., Garrett. A.B., Hoven, C., Rubio-Stipec, M., Regier, D., Moore, R., Goodman, Sh., Wu, P., and Bird, H., "Child Outpatient Mental Health Service Use: Why Doesn't Insurance Matter?” The Journal of Mental Health Policy and Economics, 1198, 1, pp.173-187.

Glied, S., Hoven, C., Garrett, A.B., Moore, R., Leaf,. P, Bird, H., Goodman, S., Regier, D., Alegria, M., "Measuring Child Mental Health Status for Services Research," Journal of Child and Family Studies, , 1997, 6(2), pp.177-190.

Gregg, Paul and Steven Machin. "Child Development and Success or Failure in the Youth Labour Market,” Center for Economic Performance, London School of Economics Discussion Paper 0397, July 1998.

Grossman, Michael and Robert Kaestner, "Effects of Education on Health" in J.R. Behrman and N. Stacey, eds., The Social Benefits of Education. University of Michigan Press, Ann Arbor MI, 1997, pp. 69-123.

Jensen, Peter S., Lori Kettle. "Are Stimulants Over-Prescribed? Treatment of ADHD in Four U.S. Communities,” Journal of the American Academy of Child \& Adolescent Psychiatry, July 99, Vol. 38 \#7, 797-805.

Korenman, Sanders, Jane Miller, and J.E. Sjaastad. "Long-term Poverty and Child Development in the United States: Results from the National Longitudinal Survey of Youth,” Children and Youth Services Review, 17 \#1\&2, 1995, 127-151.

Lipman, Ellen D.R. Offord and M.H. Boyle. "Economic Disadvantage and Child Psycho-social Morbidity,” Canadian Medical Association Journal, 151, 1994, 431-37. 
Mannuzza, Salvatore and Rachel Klein. "Long-Term Prognosis in AttentionDeficit/Hyperactivity Disorder," Child and Adolescent Psychiatric Clinics of North America, v9 \#3, July 2000, 711-726.

McLeod, J.D. and M.J. Shanahan. Poverty, Parenting and Children’s Mental Health,” American Sociological Review, 58 \#3, 1993, 351-366.

Merrell, C. And P.B. Tymms. "Inattention, Hyperactivity and Impulsiveness: Their Impact on Academic Achievement and Progress,” British Journal of Educational Psychology, 72, 2001, 4356.

Mullahy, John and Jody Sindelar. "Life-Cycle Effects of Alcoholism on Education, Earnings, and Occupation,” Inquiry, 26, 1989, 272-282.

National Institutes of Mental Health. “Attention Deficit Hyperactivity Disorder,” (Bethesda MD:NIMH) publication \#96-3572, 1996.

Offord, D., M. Boyle, P. Szatmari, N.I. Rae-Grant, P.S. Links, D.T. Cadman, J.A. Byles, J.W. Crawford, H.M. Blum, C. Byrne, H. Thomas, and C.A. Woodward. "Ontario Child Health Study: II. Six-month Prevalence of Disorder and Rates of Service Utilization,” Archives of General Psychiatry, 1987, 44: 832-36.

Offord, D., M. Boyle, Y. Racine. “Ontario Child Health Study: Correlates of Disorder,” Journal of the American Academy of Child Adolescence and Psychiatry, 1989, 28, pp.856-860.

Phipps, Shelley and Lori Curtis. "Poverty and Child Well-Being in Canada and the United States: Does it Matter How We Measure Poverty?” Final Report Applied Research Branch, Strategic Policy, Human Resources Development Canada (Ottawa: HRDC) SP-556-01-03E, September 2000.

Puzzanchera, Charles. "Self-Reported Delinquency by 12-Year-Olds, 1997,” Office of Juvenile Justice and Delinquency Prevention, U.S. Department of Justice, Fact Sheet \#3, February 2000.

Romano, Elisa, Raymond Baillargeon and Richard Tremblay. "Prevalence of HyperactivityImpulsivity and Inattention Among Canadian Children: Findings from the First Data Collection Cycle (1994-1995) of the National Longitudinal Survey of Children and Youth,” (Ottawa, Canada: Applied Research Branch Strategic Policy, Human Resources Development Canada) Final Report SP-561-01-03E, June 2002.

Sgro, M., Roberts, W., Grossman, S., Barozzino, T., "School Board Survey of Attention Deficit/Hyperactivity Disorder: Prevalence of Diagnosis and Stimulant Medication Therapy," Paediatrics and Child Health, 2000, 5(1), pp.19-23. 
Swanson, James, Dennis Cantwell, Marc Lerner, Keith McBurnett, and Greg Hanna. "Effects of Stimulant Medication on Learning in Children with ADHD,” Journal of Learning Disabilities, 24 \#4, April 1991, 219-230.

Stage, Scott and David Quiroz. “A Meta-Analysis of Interventions to Decrease Disruptive Classroom Behavior in Public Education Settings,” School Psychology Review, 1997, 26 \#3, 333-368.

U.S. Department of Health and Human Services. Mental Health: A Report to the Surgeon General (Rockville: U.S. Dept. of Health and Human Services) 1999.

Wigal, Tim, James Swanson, Roland Regino, Marc Lerner, Ihab Soliman, Ken Steinhoff, Suresh Gurbani, and Sharon Wigal. "Stimulant Medications for the Treatment of ADHD: Efficacy and Limitations,” Mental Retardation and Developmental Disabilities Research Reviews, 5, 1999, 215-224.

Williams, R., Horn, S., Daley, S., Nader, P., "Evaluation of Access to Care and Medical and Behavioral Outcomes in a School-Based Intervention Program for Attention-Deficit Hyperactivity Disorder,” Journal of School Health, 1993, 63(7), pp.294-297.

Willms, J.D., editor, Vunerable Children, University of Alberta Press: Edmonton, Alberta, 2002. 


\section{Data Appendix}

\section{Appendix Table 1: Symptoms of Inattention and Hyperactivity (Source: AAP, 2000).}

Inattention:

A) Often fails to give close attention to details or makes careless mistakes in schoolwork, work, or other activities.

B) Often has difficulty sustaining attention in tasks or play activities.

C) Often does not seem to listen when spoken to directly.

D) Often does not follow through on instructions and fails to finish schoolwork, chores, or duties in the workplace (not due to oppositional behavior or failure to understand instructions).

E) Often has difficulty organizing tasks and activities.

F) Often avoids, dislikes, or is reluctant to engage in tasks that require sustained mental effort (such as schoolwork or homework).

G) Often loses things necessary for tasks or activities (e.g. toys, school assignments, pencils, books, or tools.

H) Is often easily distracted by extraneous stimuli.

I) Is often forgetful in daily activities.

Hyperactivity:

A) Often fidgets with hands or feet or squirms in seat.

B) Often leaves seat in classroom or in other situations in which remaining seated is expected.

C) Often runs about or climbs excessively in situations in which it is inappropriate.

D) Often has difficulty playing or engaging in leisure activities quietly.

E) Is often "on the go" or often acts as if "driven by a motor".

F) Often talks excessively.

G) Often blurts out answers before questions have been completed.

H) Often has difficulty awaiting turn.

I) Often interrupts or intrudes on others (e.g. butts into conversations or games).

To be diagnosed a child must have: six or more symptoms of inattention, or six or more symptoms of hyperactivity have persisted for at least six months to a degree that is maladaptive and inconsistent with developmental level; some symptoms present before seven years of age; impairment from the symptom is present in two or more settings (such as home and school).

\section{Variable Definitions in the NLSCY}

Respondent: In the NLSCY the respondent is the "person most knowledgeable about the child" which is usually, but not always the mother (it is the mother $92 \%$ of the time). Because of this potential complication, we determine the education level of the mother using information about the PMK and the spouse of the PMK in all three survey years. We measure mother's education as follows: when the child's mother is also the PMK or the child's mother is the spouse of the PMK we use this information to calculate the mother's education. When no biological mother is present in the family in any of the three survey years we use the next closest female parent figure as the basis for calculating the mother's education. We then include dummy variables for the 
female parent figure being other than the biological mother, and/or for the PMK being other than the biological mother in all our analyses.

Parent Reported Hyperactivity - Inattention Score variables (variables ABECS06, BBECS06 and CBECS06 in cycles 1, 2 and 3 respectively) are derived using the PMK's responses to the following questions:

How often would you say that -- can't sit still, is restless or hyperactive?

How often would you say that - is distractible, has trouble sticking to an activity?

How often would you say that - fidgets?

How often would you say that - can't concentrate, can't pay attention for long?

How often would you say that - is impulsive, acts without thinking?

How often would you say that - has difficulty awaiting turn in games or groups?

How often would you say that - cannot settle to anything for more than a few moments?

How often would you say that - is inattentive?

The possible responses to these questions were: Never/Not True, Sometimes/Somewhat True or Often/Very True. The total score varies from 1-16 where a high score represents the presence of hyperactive or inattentive behaviour.

The Teacher Hyperactivity - Inattention Score variables (variables AETCS28B, BETCS28B and CETCS28B in cycles 1, 2 and 3 respectively) are derived using the respondent's teacher's responses to the same questions.

The Delinquency Variable is derived using the responses to the following questions.

I physically attack people. (cfbcq1aa)

I vandalize. (cfbcq1dd)

I steal outside my home. (cfbcq1pp)

The possible responses to these questions were Never or not true, Sometimes or somewhat true or Often of very true.

In the past 12 months, about how many times were you questioned by the police about anything that they thought you did? (cfbcbq2e)

In the past 12 months, about how many times have you run away from home? (cfbcbq2f)

The possible responses to these questions were Never, Once or Twice, Three or Four times or Five times or more.

Ages 10-11: Have you ever tried drugs or sniffed glue or solvents? (cdrcq10)The possible responses to this question are yes or no. 
Ages 12-15: Have you ever tried marijuana and cannabis products (also known as joint, pot, grass, hash)? (cdrcc10a)

Have you ever tried glue or solvents (such as paint thinner, gasoline etc)? (cdrcb10b) Ages 14-15: Have you ever tried Hallucinogens (like LSD, acid, magic mushrooms, “mesc” or PCP, “Angel dust” etc)? (cdrcb10c)

Ages 12-13: Have you ever tried other drugs (heroin, speed, PCP, crack/cocaine, LSD, acid ecstasy etc)? (cdrcc10f)

The possible responses to these questions are yes, no or I don't know what that drug is.

The variable delinquency takes on the value 1 if any of the above questions indicate delinquent behavior, takes on the value 0 only if the answers to all these questions is no or 'I don't know what that drug is', and is a missing value if any of the questions were not answered.

The above questions were asked only to children 10-15 in 1998, and hence the sample available to study delinquency is somewhat smaller than that available to study test scores. For younger children, there are a similar set of delinquency questions that are asked to the adult respondent. However, for a two year age range in which we have both self reports and adult reports (ages 10 and 11) we found that there were considerable differences in the reporting of delinquent behavior between parent and child. Given that the child's answers to these questions were recorded in writing confidentially ${ }^{22}$ and the adult answers were recorded orally, we decided to use child selfreports as the more accurate reflection of true delinquency. ${ }^{23}$

\section{Special Education:}

The special education variable is derived from a subset of respondents (the teacher in this case) who answer yes to the following question:

Does this student receive special education because a physical, emotional, behavioral, or some other problem limits the kind or amount of school work he/she can do? (cetcq21)

Respondents who answer yes are then asked a series of questions about why the student receives special education. We categorize the student as receiving special education for a mental health problem if they answered yes to any of the following reasons:

a) A learning disability.

b) An emotional or behavioral problem.

\footnotetext{
${ }^{22}$ Children are asked to respond to a written questionnaire for these questions and then to return the answers in a sealed envelope, much like the sampling procedures used in the NLSY.

${ }^{23}$ For the delinquency analysis we restrict the sample to those children who do not have missing information for any of the questions used.
} 
c) A mental disability or limitation.

d) Home environment.

\section{Reading and Mathematics Tests}

The math test was a shortened version of the Canadian Achievement Test Center's Mathematical Operations test, second edition. It measures the student's ability to do addition, subtraction, multiplication and division on whole numbers, decimals, fractions, negatives, and exponents. Problem solving using percentages and the order of operations was also measured. A separate version of the test was constructed for each grade level (except for 9 and 10 which received the same test). The 1998 test included 20 questions at each level (except for level 9-10 which had 15 questions) plus 5 questions selected from the test of the next higher level. The reading comprehension test is also from the Canadian Achievement Test, second edition. Each test consists of questions about two passages, which are designed to test the student's ability to recall information, identify the main idea, and analyze the passage. In order to avoid problems with test "ceilings", children were given a short assessment at home before they took the school tests. Children who scored perfectly on the home test, were given the test of the next highest grade level.

\section{Child Treatment}

Children are classified as taking drugs for mental health treatment if the PMK answers yes to one of the following questions:

Does he/she take the following prescribed medication on a regular basis: Ritalin? (ahlcq51b) Does he/she take the following prescribed medication on a regular basis: Tranquilizers or nerve pills? (ahlcq51c)

Children are classified as visiting a doctor for mental health treatment based on the following question:

In the past year, how many times have you seen or talked on the telephone about child's physical or mental health with: A psychiatrist or psychologist? (ahlcq48g)

\section{PMK Activity Limitations}

The PMK is asked if he/she are restricted in their daily activities. (variable ARSSD01).

The PMK Depression Score variable (variables ADPPS01, BDPPS01 and CDPPS01 in cycles 1,2 and 3 respectively) is derived using the responses to the following questions.

How often have you felt this way during the past week: I did not feel like eating, my appetite was poor?

How often have you felt this way during the past week: I felt like I could not shake off the blues even with help from family or friends?

How often have you felt this way during the past week: I had trouble keeping my mind on what I was doing? 
How often have you felt this way during the past week: I felt depressed. effort?

How often have you felt this way during the past week: I felt that everything I did was an

How often have you felt this way during the past week: I felt hopeful about the future.

How often have you felt this way during the past week: My sleep was restless.

How often have you felt this way during the past week: I was happy.

How often have you felt this way during the past week: I felt lonely.

How often have you felt this way during the past week: I enjoyed life.

How often have you felt this way during the past week: I had crying spells.

How often have you felt this way during the past week: I felt that people disliked me.

The possible responses to these questions were Rarely or none of the time (less than 1 day), Some or a little of the time (1-2 days), Occasionally or a moderate amount of the time (3-4 days) or Most or all of the time (5-7 days). The total score varies between $0-36$, where a high score represents the presence of symptoms of depression.

We used the chose a cutoff such that 10 percent of the mothers in the survey were classified as depressed.

3. Variables in the NLSY: (Note: Question numbers are from the 2000 survey).

Hyperactivity: The Behavior Problems Index is asked to parents of children 4-14. There are 26 questions asked to all children, and 2 questions asked only to children who have been to school. For each question, parents reply that the statement is often true, sometimes, true, or not true. To convert into an index, they take not true to be zero and often true or sometimes true to be a one, and then sum up the answers to the questions (so the maximum score is either 26 or 28). In addition to hyperactivity, there are also subscales for: antisocial, anxious, depressed, headstrong, hyperactive, dependent, peer conflict, and withdrawal.

The hyperactivity subscore has 5 questions:

1. He/she has difficulty concentrating, cannot pay attention for long

2. He/she is easily confused, seems to be in a fog

3. $\mathrm{He} /$ she is impulsive, acts without thinking

4. He/she has a lot of difficulty getting his/her mind off certain thoughts (has obsessions)

5. He/she is restless or overly active, cannot sit still.

This score is standardized by the child's sex and age. We convert this standardized score to one that has the same range as the score in the Canadian data.

\section{Delinquency}

Children 10-14 were consistently asked the following questions as part of the child self- 
administered questionnaire (Question 40 on the 2000 questionnaire):

In the last year, about how many times have you:

Hurt someone badly enough to need bandages or a doctor?

Taken something from a store without paying for it?

Damaged school property on purpose?

We recode the answers as zero if the answer is never, and 1 otherwise.

These questionnaires also ask whether the respondent has ever used marijuana, cocaine, LSDs, uppers, downers, amphetamines, or sniffed or huffed substances to get high. We code a one if the respondent answers yes to any of these questions.

\section{Special Education}

BKGN-29C Has he/she participated in special education or a program for handicapped children in the past year? (yes/no).

This question was only asked in 2000. Previous surveys ask about remedial education in various subjects, but we do not use these questions.

\section{Test Scores}

Peabody Individual Achievement Tests (PIATs) were administered to children with PPVT ages of 5 to 14 .

\section{Child Treatment}

HLTH-17 During the past 12 months has (child) seen a psychiatrist, psychologist, or counselor about any behavioral emotional, or mental problem?

HLTH-20 Does (child) regularly take any medicines or prescription drugs to help control his/her activity level or behavior?

\section{Maternal Activity Limitations}

Question Q11-5A is coded as 1 if the mother has any health problem that limits her ability to work, and zero otherwise.

\section{Maternal Depression:}

The mother was asked the following questions (Q11-H40CESD1B-1G in the 2000 questionnaire): 
During the past week...

I had trouble keeping my mind on what I was doing.

I felt depressed.

I felt that everything I did was an effort.

My sleep was restless.

I felt sad.

I could not get going.

Possible responses were: Rarely/None of the time/1 Day; Some/A little of the time/1-2

Days/Occasionally/Moderate Amount of the Time/3-4 Days/Most/All of the Time/5-7 Days.

These responses were given values 0,1 , 2 , or 3 .

To create a depression score, we summed the responses for each question, and chose a cutoff so that $10 \%$ of the mothers were depressed. 
Table 1: Means of Key Variables in Sample with Reading and Math Scores

Hyperactivity Score 1994

reported by teacher

Hyperactivity Score

reported by parent

Gender Difference Mean Scores

Probability score $>90$ th ptile-male

Prob. score $>90$ th ptile-female

Diagnosed ADHD
Canada Canada Sib \# Canada Sibs

\section{Child Outcomes}

Delinquent Behaviour 1998

Grade Repetition 1998

Mathematics score 1998

(/15 in Canada, /100 in US)

Reading score 1998

(/20 in Canada, /100 in US)

Special Education 1998/2000

Alternative Health Indicators

Poor Health 1994

Chronic Condition Indicator 1994

Learning Disabilities

Treatment

Drug Treatment 1994

Psychiatrist 1994

(or Psychologist in NLSCY)

Any Treatment 1994

Selected Covariates

Child Age 1994

Male Child

First Born Child

Permanent Income

Mother High School or More

Family Size 1994

Mother Teen at Child Birth

Mother's Age at Birth

Mother depressed

or activity limitation

Number of Observations
All

3.890

[4.065]

4.508

[3.487]

2.216

15.800

5.390

Sample

3.699

[3.931]

4.291

[3.414]

2.039

13.023

4.967

\subsection{7}

0.037

54.027

[23.14]

55.650

[18.2]

0.104

0.135

0.134

0.328

0.026

0.323

0.019

$0.014 \quad 0.010$

0.036

0.033

0.047

0.039

7.890

0.500

0.503

0.460

0.353

54566

56608

[33338]

[32092]

0.558

0.570

4.310

4.530

[1.063]

[0.930]

0.045

0.026

27.220

27.140

[4.709]

[4.382]

0.158

0.154

3925
U.S.

in $\mathrm{HH}$ w diff.

1300

1332

[3.797]

5.786

[3.809]

$1.248 \quad 1.269$

$12.300 \quad 12.237$

$\begin{array}{ll}7.508 & 7.253\end{array}$

$0.026 \quad 0.026$

120

248

88

608

612

32

0.502

0.492

0.075

0.072

51.622

49.946

[26.912]

[26.726]

$56.185 \quad 53.981$

[28.806] [28.943]

$0.071 \quad 0.078$
135

238

1338

1332

63

155
280
359

Notes: Canadian data from the 1994-95, 1996-97 and 1998-99 cycles of the NLSCY. Standard deviations in brackets.

U.S. data is means for 1990-1994 and for 1998 and 2000, see text. Sample includes those with non-missing test scores. 


$\begin{array}{cccc}\text { Score } & \begin{array}{c}\text { Canada } \\ \text { Teacher Report } \\ \text { \% with score }\end{array} & \begin{array}{c}\text { Canada } \\ \text { Parent Report } \\ \text { \% with score }\end{array} & \begin{array}{c}\text { U.S. } \\ \text { Parent Report } \\ \text { \% with score }\end{array} \\ 0 & 29.2 & 10.4 & 10.53 \\ 1 & 12.2 & 11.9 & 5.85 \\ 2 & \underline{9.2} & 11.5 & 5.95 \\ 3 & 7 & 10.3 & 4.23 \\ 4 & 6.5 & \underline{9.5} & 13.83 \\ 5 & 5.6 & 9.3 & 6.32 \\ 6 & 6.4 & 8.6 & 10.71 \\ 7 & 5.3 & 7.5 & 9.3 \\ 8 & 5.4 & 6.9 & 5.85 \\ 9 & 2.7 & \mathbf{4 . 8} & 11.21 \\ 10 & \mathbf{1 . 9} & 3.1 & 3.78 \\ 11 & 2 & 2 & \mathbf{4 . 7 6} \\ 12 & 1.4 & 1.4 & 3.05 \\ 13 & 1.6 & 1.1 & 1.74 \\ 14 & 1.1 & 0.9 & 1.08 \\ 15 & 1.2 & 0.7 & 0.98 \\ 16 & 1.1 & 0.3 & 0.83\end{array}$

Note: Median score is underlined. 90th percentile score indicated in bold.

Table 1c: Means of Outcomes for Children Above and Below the 90th Percentile of Hyperactivity Score

$\begin{array}{lcccc} & \text { Canada: Above } & \text { Canada: Below } & \text { U.S.: Above } & \text { U.S.: Below } \\ \text { Grade repetition } & 0.116 & 0.027 & 0.118 & 0.071 \\ \text { Delinquent } & 0.427 & 0.293 & 0.602 & 0.493 \\ \text { Mathematics Score } & 43.82 & 55.16 & 43.09 & 52.56 \\ \text { Reading Score } & 46.80 & 56.15 & 43.26 & 57.60 \\ \text { Special Education } & 0.380 & 0.070 & 0.143 & 0.063 \\ & & & & \\ \text { Drug Treatment 1994 } & 0.070 & 0.007 & 0.103 & 0.025 \\ \text { Psychiatric Treatment 1994 } & 0.096 & 0.029 & 0.174 & 0.070 \\ \text { Any Treatment 1994 } & 0.147 & 0.035 & 0.199 & 0.084\end{array}$

Note: The median teacher-reported score is used for Canada. 
Table 2: Effects of Hyperactivity on Future Outcomes

\begin{tabular}{|c|c|c|c|c|c|c|c|c|c|c|}
\hline & $\begin{array}{c}\text { [1] } \\
\text { Canada } \\
\text { Delinq. }\end{array}$ & $\begin{array}{c}\text { [2] } \\
\text { U.S. } \\
\text { Delinq. }\end{array}$ & $\begin{array}{c}\text { [3] } \\
\text { Canada } \\
\text { Grade Rep. }\end{array}$ & $\begin{array}{c}\text { [4] } \\
\text { U.S. } \\
\text { Grade Rep. }\end{array}$ & $\begin{array}{c}\text { [5] } \\
\text { Canada } \\
\text { Math }\end{array}$ & $\begin{array}{c}\text { [6] } \\
\text { U.S. } \\
\text { Math }\end{array}$ & $\begin{array}{c}\text { [7] } \\
\text { Canada } \\
\text { Reading }\end{array}$ & $\begin{array}{c}\text { [8] } \\
\text { U.S. } \\
\text { Reading }\end{array}$ & $\begin{array}{c}\text { [9] } \\
\text { Canada } \\
\text { Special Ed. }\end{array}$ & $\begin{array}{c}\text { [10] } \\
\text { U.S. } \\
\text { Special Ed. }\end{array}$ \\
\hline Hyperactivity Score 1994 & $\begin{array}{c}0.015 \\
{[6.00]^{* *}}\end{array}$ & $\begin{array}{c}0.013 \\
{[2.98]^{* *}}\end{array}$ & $\begin{array}{c}0.007 \\
{[6.99]^{* *}}\end{array}$ & $\begin{array}{c}0.004 \\
{[2.49]^{* *}}\end{array}$ & $\begin{array}{c}-1.373 \\
{[10.85]^{* *}}\end{array}$ & $\begin{array}{c}-0.868 \\
{[6.57]^{* *}}\end{array}$ & $\begin{array}{c}-0.850 \\
{[8.18]^{* *}}\end{array}$ & $\begin{array}{c}-1.176 \\
{[8.14]^{* *}}\end{array}$ & $\begin{array}{c}0.023 \\
{[8.79]^{* *}}\end{array}$ & $\begin{array}{c}0.008 \\
{[3.85]^{* *}}\end{array}$ \\
\hline $\begin{array}{l}\text { Average Income } \\
\text { (in 100,000) }\end{array}$ & $\begin{array}{l}0.008 \\
{[0.33]}\end{array}$ & $\begin{array}{l}-0.086 \\
{[1.21]}\end{array}$ & $\begin{array}{c}-0.038 \\
{[4.28]^{* *}}\end{array}$ & $\begin{array}{c}-0.053 \\
{[2.77]^{* *}}\end{array}$ & $\begin{array}{c}7.117 \\
{[4.72]^{* *}}\end{array}$ & $\begin{array}{c}15.382 \\
{[6.87]^{* *}}\end{array}$ & $\begin{array}{c}5.220 \\
{[4.69]^{* *}}\end{array}$ & $\begin{array}{c}13.977 \\
{[5.51]^{* *}}\end{array}$ & $\begin{array}{l}-0.031 \\
{[1.44]}\end{array}$ & $\begin{array}{l}-0.024 \\
{[0.73]}\end{array}$ \\
\hline $\begin{array}{l}\text { Adult Respondent } \\
\text { Immigrant }\end{array}$ & $\begin{array}{r}-0.040 \\
{[1.23]}\end{array}$ & & $\begin{array}{l}-0.009 \\
{[0.94]}\end{array}$ & & $\begin{array}{c}0.514 \\
{[0.28]}\end{array}$ & & $\begin{array}{l}0.830 \\
{[0.56]}\end{array}$ & & $\begin{array}{c}0.078 \\
{[2.00]^{*}}\end{array}$ & \\
\hline Black & & $\begin{array}{l}-0.017 \\
{[0.46]}\end{array}$ & & $\begin{array}{l}0.007 \\
{[0.50]}\end{array}$ & & $\begin{array}{c}-8.787 \\
{[6.13]^{* *}}\end{array}$ & & $\begin{array}{l}-2.835 \\
{[1.76]^{*}}\end{array}$ & & $\begin{array}{r}-0.023 \\
{[1.13]}\end{array}$ \\
\hline Hispanic & & $\begin{array}{c}0.03 \\
{[0.83]}\end{array}$ & & $\begin{array}{c}0.027 \\
{[2.05]^{* *}}\end{array}$ & & $\begin{array}{l}-12.485 \\
{[8.58]^{* *}}\end{array}$ & & $\begin{array}{c}-9.391 \\
{[5.69]^{* *}}\end{array}$ & & $\begin{array}{c}0.004 \\
{[0.16]}\end{array}$ \\
\hline Male & $\begin{array}{c}0.099 \\
{[5.34]^{* *}}\end{array}$ & $\begin{array}{c}0.029 \\
{[1.03]}\end{array}$ & $\begin{array}{l}0.005 \\
{[0.79]}\end{array}$ & $\begin{array}{c}0.016 \\
{[1.70]^{*}}\end{array}$ & $\begin{array}{c}1.721 \\
{[1.78]^{*}}\end{array}$ & $\begin{array}{c}4.539 \\
{[4.65]^{* *}}\end{array}$ & $\begin{array}{l}-0.210 \\
{[0.27]}\end{array}$ & $\begin{array}{l}-0.444 \\
{[0.41]}\end{array}$ & $\begin{array}{l}0.023 \\
{[1.43]}\end{array}$ & $\begin{array}{c}0.034 \\
{[2.46]^{* *}}\end{array}$ \\
\hline First Born Child & $\begin{array}{l}-0.032 \\
{[1.55]}\end{array}$ & $\begin{array}{c}-0.062 \\
{[1.97]^{*}}\end{array}$ & $\begin{array}{l}-0.003 \\
{[0.49]}\end{array}$ & $\begin{array}{l}-0.003 \\
{[0.29]}\end{array}$ & $\begin{array}{c}3.095 \\
{[2.89]^{* *}}\end{array}$ & $\begin{array}{c}2.221 \\
{[1.94]^{*}}\end{array}$ & $\begin{array}{c}5.185 \\
{[6.06]^{* *}}\end{array}$ & $\begin{array}{c}5.375 \\
{[4.42]^{* *}}\end{array}$ & $\begin{array}{l}-0.003 \\
{[0.19]}\end{array}$ & $\begin{array}{l}-0.015 \\
{[0.85]}\end{array}$ \\
\hline Log Family Size 1994 & $\begin{array}{l}0.059 \\
{[1.23]}\end{array}$ & $\begin{array}{l}-0.076 \\
{[1.35]}\end{array}$ & $\begin{array}{l}0.007 \\
{[0.41]}\end{array}$ & $\begin{array}{c}0 \\
{[0.02]}\end{array}$ & $\begin{array}{c}0.694 \\
{[0.27]}\end{array}$ & $\begin{array}{c}-8.366 \\
{[3.61]^{* *}}\end{array}$ & $\begin{array}{l}2.160 \\
{[1.10]}\end{array}$ & $\begin{array}{c}-9.785 \\
{[3.63]^{* *}}\end{array}$ & $\begin{array}{l}0.014 \\
{[0.34]}\end{array}$ & $\begin{array}{l}0.035 \\
{[0.90]}\end{array}$ \\
\hline Two Parent Family 1994 & $\begin{array}{c}-0.111 \\
{[3.31]^{* *}}\end{array}$ & $\begin{array}{c}-0.063 \\
{[1.94]^{*}}\end{array}$ & $\begin{array}{l}0.000 \\
{[0.04]}\end{array}$ & $\begin{array}{c}-0.021 \\
{[1.83]^{*}}\end{array}$ & $\begin{array}{c}0.133 \\
{[0.08]}\end{array}$ & $\begin{array}{c}2.128 \\
{[1.74]^{*}}\end{array}$ & $\begin{array}{l}-0.210 \\
{[0.27]}\end{array}$ & $\begin{array}{l}1.773 \\
{[1.25]}\end{array}$ & $\begin{array}{l}-0.048 \\
{[1.45]}\end{array}$ & $\begin{array}{l}-0.027 \\
{[1.45]}\end{array}$ \\
\hline Mother's Age at Birth & $\begin{array}{l}-0.001 \\
{[0.61]}\end{array}$ & $\begin{array}{c}-0.019 \\
{[2.55]^{* *}}\end{array}$ & $\begin{array}{l}0.000 \\
{[0.12]}\end{array}$ & $\begin{array}{l}-0.001 \\
{[0.60]}\end{array}$ & $\begin{array}{c}0.260 \\
{[2.16]^{* *}}\end{array}$ & $\begin{array}{c}0.543 \\
{[2.21]^{* *}}\end{array}$ & $\begin{array}{c}0.405 \\
{[4.17]^{* *}}\end{array}$ & $\begin{array}{c}0.477 \\
{[1.76]^{*}}\end{array}$ & $\begin{array}{l}-0.001 \\
{[0.49]}\end{array}$ & $\begin{array}{c}0.002 \\
{[0.78]}\end{array}$ \\
\hline Teen Mother & $\begin{array}{l}0.035 \\
{[0.70]}\end{array}$ & $\begin{array}{c}-0.113 \\
{[1.99]^{* *}}\end{array}$ & $\begin{array}{l}-0.007 \\
{[0.40]}\end{array}$ & $\begin{array}{l}0.007 \\
{[0.22]}\end{array}$ & $\begin{array}{c}-5.376 \\
{[2.26]^{* *}}\end{array}$ & $\begin{array}{l}2.062 \\
{[0.43]}\end{array}$ & $\begin{array}{c}-4.820 \\
{[2.68]^{* *}}\end{array}$ & $\begin{array}{l}6.905 \\
{[0.95]}\end{array}$ & $\begin{array}{l}0.065 \\
{[1.27]}\end{array}$ & $\begin{array}{c}0.000 \\
{[.]}\end{array}$ \\
\hline Mother High School plus & $\begin{array}{l}-0.021 \\
{[1.08]}\end{array}$ & $\begin{array}{l}-0.044 \\
{[1.25]}\end{array}$ & $\begin{array}{c}-0.015 \\
{[2.25]^{* *}}\end{array}$ & $\begin{array}{c}-0.085 \\
{[5.31]^{* *}}\end{array}$ & $\begin{array}{c}2.321 \\
{[2.21]^{* *}}\end{array}$ & $\begin{array}{c}8.487 \\
{[6.19]^{* *}}\end{array}$ & $\begin{array}{c}3.180 \\
{[3.84]^{* *}}\end{array}$ & $\begin{array}{c}11.635 \\
{[7.23]^{* *}}\end{array}$ & $\begin{array}{l}-0.017 \\
{[1.02]}\end{array}$ & $\begin{array}{l}-0.005 \\
{[0.22]}\end{array}$ \\
\hline $\begin{array}{l}\text { PMK depressed or } \\
\text { activity limit in } 1994\end{array}$ & $\begin{array}{l}0.034 \\
{[1.29]}\end{array}$ & $\begin{array}{l}-0.018 \\
{[0.55]}\end{array}$ & $\begin{array}{l}0.004 \\
{[0.41]}\end{array}$ & $\begin{array}{l}0.002 \\
{[0.14]}\end{array}$ & $\begin{array}{l}-0.674 \\
{[0.49]}\end{array}$ & $\begin{array}{l}-2.499 \\
{[1.87]^{*}}\end{array}$ & $\begin{array}{l}-0.700 \\
{[0.67]}\end{array}$ & $\begin{array}{l}-0.491 \\
{[0.33]}\end{array}$ & $\begin{array}{l}0.024 \\
{[0.97]}\end{array}$ & $\begin{array}{l}0.025 \\
{[1.19]}\end{array}$ \\
\hline Age 4 (in 1994) & & $\begin{array}{c}0 \\
{[.]}\end{array}$ & $\begin{array}{c}-0.036 \\
{[3.11]^{* *}}\end{array}$ & $\begin{array}{c}0.059 \\
{[2.46]^{* *}}\end{array}$ & $\begin{array}{c}6.450 \\
{[2.42]^{* *}}\end{array}$ & $\begin{array}{l}-2.306 \\
{[0.58]}\end{array}$ & $\begin{array}{l}1.145 \\
{[0.49]}\end{array}$ & $\begin{array}{l}-2.062 \\
{[0.50]}\end{array}$ & $\begin{array}{c}0.000 \\
{[0.00]}\end{array}$ & $\begin{array}{c}0.006 \\
{[0.16]}\end{array}$ \\
\hline Age 5 & $\begin{array}{c}-0.730 \\
{[16.02]^{* *}}\end{array}$ & $\begin{array}{c}0 \\
{[.]}\end{array}$ & $\begin{array}{l}0.005 \\
{[0.37]}\end{array}$ & $\begin{array}{l}0.014 \\
{[0.63]}\end{array}$ & $\begin{array}{c}5.176 \\
{[2.92]^{* *}}\end{array}$ & $\begin{array}{l}-0.533 \\
{[0.13]}\end{array}$ & $\begin{array}{l}-1.550 \\
{[1.12]}\end{array}$ & $\begin{array}{l}-4.554 \\
{[1.10]}\end{array}$ & $\begin{array}{l}0.032 \\
{[0.58]}\end{array}$ & $\begin{array}{l}0.005 \\
{[0.12]}\end{array}$ \\
\hline Age 6 & $\begin{array}{c}-0.216 \\
{[6.88]^{* *}}\end{array}$ & $\begin{array}{c}0 \\
{[.]}\end{array}$ & $\begin{array}{l}-0.010 \\
{[0.83]}\end{array}$ & $\begin{array}{c}-0.029 \\
{[1.66]^{*}}\end{array}$ & $\begin{array}{c}5.423 \\
{[3.13]^{* *}}\end{array}$ & $\begin{array}{l}-0.621 \\
{[0.16]}\end{array}$ & $\begin{array}{c}-2.985 \\
{[2.22]^{* *}}\end{array}$ & $\begin{array}{l}-3.063 \\
{[0.75]}\end{array}$ & $\begin{array}{c}0.009 \\
{[0.16]}\end{array}$ & $\begin{array}{l}-0.017 \\
{[0.46]}\end{array}$ \\
\hline Age 7 & $\begin{array}{c}-0.244 \\
{[7.95]^{* *}}\end{array}$ & $\begin{array}{c}0 \\
{[.]}\end{array}$ & $\begin{array}{l}-0.017 \\
{[1.43]}\end{array}$ & $\begin{array}{l}-0.024 \\
{[1.38]}\end{array}$ & $\begin{array}{c}5.396 \\
{[3.02]^{* *}}\end{array}$ & $\begin{array}{l}-1.412 \\
{[0.36]}\end{array}$ & $\begin{array}{c}-4.985 \\
{[3.44]^{* *}}\end{array}$ & $\begin{array}{l}-4.855 \\
{[1.17]}\end{array}$ & $\begin{array}{c}0.022 \\
{[0.40]}\end{array}$ & $\begin{array}{l}0.009 \\
{[0.23]}\end{array}$ \\
\hline Age 8 & $\begin{array}{c}-0.224 \\
{[7.22]^{* *}}\end{array}$ & $\begin{array}{c}-0.187 \\
{[3.75]^{* *}}\end{array}$ & $\begin{array}{l}-0.019 \\
{[1.69]^{*}}\end{array}$ & $\begin{array}{l}-0.002 \\
{[0.10]}\end{array}$ & $\begin{array}{c}-5.523 \\
{[3.33]^{* *}}\end{array}$ & $\begin{array}{l}-3.178 \\
{[0.80]}\end{array}$ & $\begin{array}{c}-4.455 \\
{[3.27]^{* *}}\end{array}$ & $\begin{array}{l}-3.991 \\
{[0.95]}\end{array}$ & $\begin{array}{l}-0.013 \\
{[0.22]}\end{array}$ & $\begin{array}{l}0.068 \\
{[1.64]}\end{array}$ \\
\hline Age 9 & $\begin{array}{c}-0.127 \\
{[3.92]^{* *}}\end{array}$ & $\begin{array}{c}-0.134 \\
{[3.71]^{* *}}\end{array}$ & $\begin{array}{l}-0.004 \\
{[0.32]}\end{array}$ & $\begin{array}{l}0.015 \\
{[0.84]}\end{array}$ & $\begin{array}{c}-3.682 \\
{[2.11]^{* *}}\end{array}$ & $\begin{array}{l}-3.866 \\
{[0.95]}\end{array}$ & $\begin{array}{c}-7.045 \\
{[5.20]^{* *}}\end{array}$ & $\begin{array}{l}-3.917 \\
{[0.93]}\end{array}$ & $\begin{array}{l}0.077 \\
{[1.26]}\end{array}$ & $\begin{array}{c}0.000 \\
{[.]}\end{array}$ \\
\hline Age 10 & $\begin{array}{l}-0.016 \\
{[0.46]}\end{array}$ & $\begin{array}{c}-0.104 \\
{[3.00]^{* *}}\end{array}$ & $\begin{array}{c}-0.024 \\
{[2.23]^{* *}}\end{array}$ & $\begin{array}{l}0.023 \\
{[1.18]}\end{array}$ & $\begin{array}{c}-6.410 \\
{[3.70]^{* *}}\end{array}$ & $\begin{array}{l}-1.725 \\
{[0.40]}\end{array}$ & $\begin{array}{c}-3.730 \\
{[2.80]^{* *}}\end{array}$ & $\begin{array}{l}-2.429 \\
{[0.55]}\end{array}$ & $\begin{array}{l}0.079 \\
{[1.03]}\end{array}$ & $\begin{array}{c}0.000 \\
{[.]}\end{array}$ \\
\hline Constant & $\begin{array}{c}0.359 \\
{[3.54]^{* *}}\end{array}$ & $\begin{array}{c}1.165 \\
{[6.01]^{* *}}\end{array}$ & $\begin{array}{l}0.040 \\
{[1.15]}\end{array}$ & $\begin{array}{c}0.163 \\
{[2.34]^{* *}}\end{array}$ & $\begin{array}{c}46.276 \\
{[8.06]^{* *}}\end{array}$ & $\begin{array}{c}45.458 \\
{[5.38]^{* *}}\end{array}$ & $\begin{array}{c}44.025 \\
{[9.91]^{* *}}\end{array}$ & $\begin{array}{c}54.236 \\
{[5.88]^{* *}}\end{array}$ & $\begin{array}{l}0.063 \\
{[0.62]}\end{array}$ & $\begin{array}{r}-0.080 \\
{[0.75]}\end{array}$ \\
\hline Observations & 2516 & 1303 & 3925 & 3240 & 2209 & 2501 & 2209 & 2501 & 1357 & 1401 \\
\hline R-squared & 0.090 & 0.06 & 0.040 & 0.06 & 0.150 & 0.23 & 0.120 & 0.2 & 0.14 & 0.05 \\
\hline
\end{tabular}

Notes: Canadian data are from the 1994-95, 1996-97 and 1998-99 cycles of the NLSCY. Robust t-statistics are in brackets. A * is significant at the $90 \%$ level. A ** indicates significants at $95 \%$. Standard errors clustered at the household level. In the U.S. data, the "1994" variables are means over the period 1988-1994, while the 1998 values are means for 1998 and 2000. Regressions for Canada also included indicators for whether the PMK was female, and for whether income was imputed. 
Table 3: Robustness of Effects of Hyperactivity on Future Outcomes

\begin{tabular}{|c|c|c|c|c|c|c|c|c|c|c|}
\hline 1. OLS from Table 2 & $\begin{array}{c}\text { [1] } \\
\text { Canada } \\
\text { Delinq. }\end{array}$ & $\begin{array}{c}\text { [2] } \\
\text { U.S. } \\
\text { Delinq. }\end{array}$ & $\begin{array}{c}\text { [3] } \\
\text { Canada } \\
\text { Grade Rep. }\end{array}$ & $\begin{array}{c}\text { [4] } \\
\text { U.S. } \\
\text { Grade Rep. }\end{array}$ & $\begin{array}{c}\text { [5] } \\
\text { Canada } \\
\text { Math }\end{array}$ & $\begin{array}{c}\text { [6] } \\
\text { U.S. } \\
\text { Math }\end{array}$ & $\begin{array}{c}\text { [7] } \\
\text { Canada } \\
\text { Reading }\end{array}$ & $\begin{array}{c}\text { [8] } \\
\text { U.S. } \\
\text { Reading }\end{array}$ & $\begin{array}{c}\text { [9] } \\
\text { Canada } \\
\text { Special Ed. }\end{array}$ & $\begin{array}{c}\text { [10] } \\
\text { U.S. } \\
\text { Special Ed. }\end{array}$ \\
\hline Hyperactivity Score 1994 & $\begin{array}{c}0.015 \\
{[6.00]^{* *}}\end{array}$ & $\begin{array}{c}0.013 \\
{[2.98]^{* *}}\end{array}$ & $\begin{array}{c}0.007 \\
{[6.99]^{* *}}\end{array}$ & $\begin{array}{c}0.004 \\
{[2.49]^{*}}\end{array}$ & $\begin{array}{c}-1.373 \\
{[10.85]^{* *}}\end{array}$ & $\begin{array}{c}-0.868 \\
{[6.57]^{* *}}\end{array}$ & $\begin{array}{c}-0.849 \\
{[8.18]^{* *}}\end{array}$ & $\begin{array}{c}-1.176 \\
{[8.14]^{* *}}\end{array}$ & $\begin{array}{c}0.023 \\
{[8.79]^{* *}}\end{array}$ & $\begin{array}{c}0.008 \\
{[3.85]^{* *}}\end{array}$ \\
\hline Average Income $(100,000)$ & $\begin{array}{l}0.008 \\
{[0.33]}\end{array}$ & $\begin{array}{c}-0.086 \\
{[1.21]}\end{array}$ & $\begin{array}{c}-0.038 \\
{[4.28]^{* *}}\end{array}$ & $\begin{array}{c}-0.053 \\
{[2.77]^{* *}}\end{array}$ & $\begin{array}{c}7.117 \\
{[4.72]^{* *}}\end{array}$ & $\begin{array}{c}15.382 \\
{[6.87]^{* *}}\end{array}$ & $\begin{array}{c}5.221 \\
{[4.69]^{* *}}\end{array}$ & $\begin{array}{c}13.977 \\
{[5.51]^{* *}}\end{array}$ & $\begin{array}{l}-0.031 \\
{[1.44]}\end{array}$ & $\begin{array}{l}-0.024 \\
{[0.73]}\end{array}$ \\
\hline Observations & 2516 & 1303 & 3925 & 3240 & 2209 & 2501 & 2209 & 2501 & 1357 & 1401 \\
\hline R-squared & 0.090 & 0.06 & 0.040 & 0.06 & 0.150 & 0.23 & 0.120 & 0.2 & 0.140 & 0.050 \\
\hline \multicolumn{11}{|l|}{ 2. Fixed Effects } \\
\hline Hyperactivity Score 1994 & $\begin{array}{c}0.008 \\
{[1.08]}\end{array}$ & $\begin{array}{c}-0.015 \\
{[1.04]}\end{array}$ & $\begin{array}{c}0.005 \\
{[2.46]^{* *}}\end{array}$ & $\begin{array}{c}0.005 \\
{[1.85]^{*}}\end{array}$ & $\begin{array}{c}-1.179 \\
{[3.94]^{* *}}\end{array}$ & $\begin{array}{c}-0.996 \\
{[4.00]^{* *}}\end{array}$ & $\begin{array}{c}-0.66 \\
{[2.70]^{* *}}\end{array}$ & $\begin{array}{c}-0.834 \\
{[3.14]^{* *}}\end{array}$ & $\begin{array}{c}0.021 \\
{[2.95]^{* *}}\end{array}$ & $\begin{array}{c}0.009 \\
{[1.74]^{*}}\end{array}$ \\
\hline Observations & 2514 & 1304 & 3923 & 3241 & 2208 & 2501 & 2208 & 2501 & 1357 & 1401 \\
\hline R-squared & 0.9 & 0.9 & 0.85 & 0.76 & 0.91 & 0.86 & 0.9 & 0.86 & 0.95 & 0.84 \\
\hline \multicolumn{11}{|c|}{ 3. FE - Dummy Variable for Hyperactivity Above 90th Percentile } \\
\hline Hperactivity Score 1994 & -0.087 & 0.118 & 0.064 & 0.07 & -9.468 & -3.989 & -5.930 & -5.778 & 0.381 & 0.121 \\
\hline Above 90th percentile & {$[1.02]$} & {$[0.86]$} & {$[2.89]^{* *}$} & {$[2.68]^{* *}$} & {$[2.59] * *$} & {$[1.46]$} & {$[2.01]^{* *}$} & {$[1.98]^{* *}$} & {$[4.92]^{* *}$} & {$[2.00]^{* *}$} \\
\hline Observations & 2514 & 1304 & 3923 & 3241 & 2208 & 2501 & 2208 & 2501 & 1357 & 1401 \\
\hline R-squared & 0.9 & 0.9 & 0.85 & 0.76 & 0.9 & 0.86 & 0.9 & 0.86 & 0.96 & 0.84 \\
\hline \multicolumn{11}{|c|}{ 4. FE - Dropping Children with Diagnosed Learning Disabilities } \\
\hline Hperactivity Score 1994 & $\begin{array}{c}0.006 \\
{[0.86]}\end{array}$ & $\begin{array}{l}-0.017 \\
{[1.16]}\end{array}$ & $\begin{array}{c}0.003 \\
{[1.69]^{*}}\end{array}$ & $\begin{array}{c}0.004 \\
{[1.80]^{*}}\end{array}$ & $\begin{array}{c}-1.294 \\
{[4.21]^{* *}}\end{array}$ & $\begin{array}{c}-0.954 \\
{[3.79]^{* *}}\end{array}$ & $\begin{array}{c}-0.675 \\
{[2.69]^{* *}}\end{array}$ & $\begin{array}{c}-0.762 \\
{[2.85]^{* *}}\end{array}$ & $\begin{array}{c}0.018 \\
{[2.65]^{* *}}\end{array}$ & $\begin{array}{l}0.006 \\
{[1.36]}\end{array}$ \\
\hline Observations & 2447 & 1257 & 3819 & 3152 & 2160 & 2456 & 2160 & 2456 & 1327 & 1202 \\
\hline R-squared & 0.9 & 0.91 & 0.85 & 0.79 & 0.91 & 0.859 & 0.9 & 0.86 & 0.95 & 0.84 \\
\hline \multicolumn{11}{|c|}{ 5. FE - Including Children ages 4-7 in 1994 only } \\
\hline Hperactivity Score 1994 & & & $\begin{array}{c}0.008 \\
{[1.85]^{*}}\end{array}$ & $\begin{array}{c}0.004 \\
{[2.43]^{* *}}\end{array}$ & $\begin{array}{l}0.527 \\
{[0.79]}\end{array}$ & $\begin{array}{c}-0.826 \\
{[5.25]^{* *}}\end{array}$ & $\begin{array}{l}-0.695 \\
{[1.42]}\end{array}$ & $\begin{array}{c}-1.03 \\
{[5.97]^{* *}}\end{array}$ & $\begin{array}{c}0.022 \\
{[2.31]^{* *}}\end{array}$ & $\begin{array}{c}0.007 \\
{[3.63]^{* *}}\end{array}$ \\
\hline Observations & & & 1734 & 1469 & 998 & 1491 & 998 & 1490 & 1002 & 12.02 \\
\hline R-squared & & & 0.94 & 0.083 & 0.96 & 0.248 & 0.97 & 0.205 & 0.98 & 0.032 \\
\hline \multicolumn{11}{|c|}{ 6. FE, Instrumenting Teacher Report with Parent Report of Hyperactivity Score } \\
\hline Hyperactivity Score 1994 & $\begin{array}{l}0.012 \\
{[0.71]}\end{array}$ & & $\begin{array}{c}0.010 \\
{[2.13]^{* *}}\end{array}$ & & $\begin{array}{c}-1.456 \\
{[1.99]^{* *}}\end{array}$ & & $\begin{array}{l}-0.370 \\
{[0.62]}\end{array}$ & & $\begin{array}{c}0.083 \\
{[3.09]^{* *}}\end{array}$ & \\
\hline Observations & 2506 & & 3907 & & 2197 & & 2197 & & 1352 & \\
\hline R-squared & 0.001 & & 0.02 & & 0.08 & & 0.08 & & 0.05 & \\
\hline \multicolumn{11}{|c|}{ 7. FE, Using Diagnosed ADHD Cases } \\
\hline Child Diagnosed w ADHD & & $\begin{array}{l}0.395 \\
{[1.62]}\end{array}$ & & $\begin{array}{l}-0.053 \\
{[1.20]}\end{array}$ & & $\begin{array}{l}-9.161 \\
{[1.65]^{*}}\end{array}$ & & $\begin{array}{l}-5.195 \\
{[0.87]}\end{array}$ & & $\begin{array}{c}0.64 \\
{[3.49]^{* *}}\end{array}$ \\
\hline Observations & & 1304 & & 3240 & & 2500 & & 2500 & & 1401 \\
\hline R-squared & & 0.9 & & 0.76 & & 0.86 & & 0.86 & & 0.85 \\
\hline
\end{tabular}

Notes: Robust t-statistics in brackets. A * indicates significance at the $90 \%$ level. A ** indicates significance at $95 \%$.

Standard errors clustered at the household level.

To compare effects on reading and math scores, multiply the Canadian coefficients by 5 and 6.67 respectively.

The first stage F-statistic for test that the parent score is 0 in our IV models is 154 (t-statistic of 12). 
Table 4: Alternative Ways of Handling Treated Children

\begin{tabular}{|c|c|c|c|c|c|c|c|c|c|}
\hline & $\begin{array}{c}\text { [1] } \\
\text { Canada } \\
\text { Delinq. }\end{array}$ & $\begin{array}{c}\text { [2] } \\
\text { U.S. } \\
\text { Delinq. }\end{array}$ & $\begin{array}{c}\text { [3] } \\
\text { Canada } \\
\text { Grade Rep. }\end{array}$ & $\begin{array}{c}\text { [4] } \\
\text { U.S. } \\
\text { Grade Rep. }\end{array}$ & $\begin{array}{c}\text { [5] } \\
\text { Canada } \\
\text { Math }\end{array}$ & $\begin{array}{c}\text { [6] } \\
\text { U.S. } \\
\text { Math }\end{array}$ & $\begin{array}{c}\text { [7] } \\
\text { Canada } \\
\text { Reading }\end{array}$ & $\begin{array}{c}\text { [8] } \\
\text { U.S. } \\
\text { Reading }\end{array}$ & $\begin{array}{r}\text { I } \\
\text { Ca } \\
\text { Spec }\end{array}$ \\
\hline \multicolumn{10}{|c|}{ 1. FE - Excluding Children Treated in 1994} \\
\hline Hyperactivity Score, 1994 & $\begin{array}{l}0.007 \\
{[0.91]}\end{array}$ & $\begin{array}{l}-0.023 \\
{[1.38]}\end{array}$ & $\begin{array}{c}0.004 \\
{[2.00]^{* *}}\end{array}$ & $\begin{array}{l}0.003 \\
{[1.29]}\end{array}$ & $\begin{array}{c}-1.242 \\
{[3.93]^{* *}}\end{array}$ & $\begin{array}{c}-0.770 \\
{[2.77]^{* *}}\end{array}$ & $\begin{array}{c}-0.639 \\
{[2.45]^{* *}}\end{array}$ & $\begin{array}{c}-0.694 \\
{[2.37]^{* *}}\end{array}$ & $\begin{array}{r}0 . \\
{[3.5}\end{array}$ \\
\hline Observations & 2382 & 1108 & 3735 & 2900 & 2096 & 2290 & 2096 & 2289 & 1: \\
\hline R-squared & 0.9 & 0.91 & 0.85 & 0.79 & 0.91 & 0.87 & 0.9 & 0.87 & 0 \\
\hline \multicolumn{10}{|c|}{ 2. FE - Assigning Treated Children the 90th Percentile Score } \\
\hline Hyperactivity Score, 1994 & $\begin{array}{l}0.008 \\
{[1.23]}\end{array}$ & $\begin{array}{l}-0.017 \\
{[1.23]}\end{array}$ & $\begin{array}{c}0.004 \\
{[2.31]^{* *}}\end{array}$ & $\begin{array}{l}0.004 \\
{[1.62]}\end{array}$ & $\begin{array}{c}-1.389 \\
{[4.69]^{* *}}\end{array}$ & $\begin{array}{c}-0.968 \\
{[3.99]^{* *}}\end{array}$ & $\begin{array}{c}-0.792 \\
{[3.25]^{* *}}\end{array}$ & $\begin{array}{c}-0.847 \\
{[3.27]^{* *}}\end{array}$ & $\begin{array}{r}0 . \\
{[3 .}\end{array}$ \\
\hline Observations & 2515 & 1304 & 3923 & 3241 & 2208 & 2501 & 2208 & 2501 & 1: \\
\hline R-squared & 0.9 & 0.901 & 0.85 & 0.762 & 0.91 & 0.858 & 0.9 & 0.858 & 0 \\
\hline \multicolumn{10}{|c|}{ 3. FE - Excluding Children Treated in 1994 - Hyperactivity above 90th Percentile } \\
\hline Hyperactivity Score, 1994 & $\begin{array}{c}-0.111 \\
{[1.21]}\end{array}$ & $\begin{array}{l}-0.044 \\
{[0.28]}\end{array}$ & $\begin{array}{c}0.065 \\
{[2.84]^{* *}}\end{array}$ & $\begin{array}{c}0.063 \\
{[2.11]^{* *}}\end{array}$ & $\begin{array}{c}-9.675 \\
{[2.54]^{* *}}\end{array}$ & $\begin{array}{l}-4.520 \\
{[1.43]}\end{array}$ & $\begin{array}{l}-5.081 \\
{[1.63]}\end{array}$ & $\begin{array}{c}-6.390 \\
{[1.93]^{*}}\end{array}$ & $\begin{array}{r}0 . \\
{[5 .]}\end{array}$ \\
\hline Observations & 2382 & 1108 & 3735 & 2900 & 2096 & 2290 & 2096 & 2289 & 1: \\
\hline R-squared & 0.9 & 0.91 & 0.85 & 0.79 & 0.91 & 0.87 & 0.9 & 0.87 & 0 \\
\hline \multicolumn{10}{|c|}{ 4. FE - Assigning Treated Children the 90th Percentile Score - Hyperactivty above 90th Percentile } \\
\hline Hyperactivity Score, 1994 & $\begin{array}{c}-0.047 \\
{[.61]}\end{array}$ & $\begin{array}{l}-0.046 \\
{[0.29]}\end{array}$ & $\begin{array}{c}0.059 \\
{[2.95]^{* *}}\end{array}$ & $\begin{array}{c}0.962 \\
{[2.09]^{* *}}\end{array}$ & $\begin{array}{c}-12.099 \\
{[3.63]^{* *}}\end{array}$ & $\begin{array}{l}-3.020 \\
{[1.02]}\end{array}$ & $\begin{array}{c}-7.514 \\
{[2.77]^{* *}}\end{array}$ & $\begin{array}{c}-7.930 \\
{[2.52]^{* *}}\end{array}$ & $\begin{array}{r}0 . \\
{[5.6}\end{array}$ \\
\hline Observations & 2515 & 1304 & 3923 & 3241 & 2208 & 2501 & 2208 & 2501 & 1: \\
\hline R-squared & 0.9 & 0.9 & 0.85 & 0.763 & 0.91 & 0.983 & 0.9 & 0.858 & 0 \\
\hline
\end{tabular}

Notes: See table 3 
Table 5: Differences Between Boys and Girls

\begin{tabular}{|c|c|c|c|c|c|c|c|c|c|}
\hline [1] & [2] & [3] & [4] & [5] & [6] & [7] & [8] & [9] & [10] \\
\hline $\begin{array}{l}\text { Canada } \\
\text { Deling. }\end{array}$ & $\begin{array}{c}\text { U.S. } \\
\text { Deling. }\end{array}$ & $\begin{array}{c}\text { Canada } \\
\text { Grade Rep. }\end{array}$ & $\begin{array}{c}\text { U.S. } \\
\text { Grade Rep. }\end{array}$ & $\begin{array}{l}\text { Canada } \\
\text { Math }\end{array}$ & $\begin{array}{l}\text { U.S. } \\
\text { Math }\end{array}$ & $\begin{array}{l}\text { Canada } \\
\text { Reading }\end{array}$ & $\begin{array}{c}\text { U.S. } \\
\text { Reading }\end{array}$ & $\begin{array}{c}\text { Canada } \\
\text { Special Ed.S }\end{array}$ & $\begin{array}{c}\text { U.S. } \\
\text { Special Ed. }\end{array}$ \\
\hline
\end{tabular}

1. FE - Interaction of Hyperactivity Score with Male

Hyperactivity Score, 1994

$\begin{array}{cccccccccc}0.008 & -0.006 & 0.003 & 0.004 & -0.962 & -0.990 & -0.585 & -0.689 & 0.007 & 0.005 \\ {[0.68]} & {[0.38]} & {[1.02]} & {[1.43]} & {[2.20]^{* *}} & {[3.48]^{* *}} & {[1.64]} & {[2.25]^{* *}} & {[0.61]} & {[0.97]} \\ 0.000 & -0.006 & 0.003 & -0.001 & -0.352 & 0.184 & -0.122 & -0.303 & 0.020 & 0.004 \\ {[0.01]} & {[0.60]} & {[0.83]} & {[0.64]} & {[0.68]} & {[0.90]} & {[0.29]} & {[1.38]} & {[1.54]} & {[0.89]} \\ 2514 & 1304 & 3923 & 3241 & 2207 & 2501 & 2207 & 2501 & 1356 & 1401 \\ 0.90 & 0.90 & 0.85 & 0.76 & 0.91 & 0.86 & 0.90 & 0.86 & 0.95 & 0.84\end{array}$

\section{FE - Interaction of 90th percentile of Hyperactivity Score with Male}

$\begin{array}{lll}-0.064 & 0.226 & 0.097\end{array}$

Male*Hyper Score

[1.13]

$[2.48]^{* *}$

0.097

$-9.996$

$[2.45]^{* *}$

[1.57]
0.745

[0.16]

$-0.126$

[1.03]

$-0.040$

0.745

Observations

2514

1304

3923

[0.88]

[0.10]
2207

R-squared

0.90

0.90

0.85

0.75

0.91

$\begin{array}{cc}2.970 & -8.268 \\ {[0.72]} & {[1.61]} \\ -9.570 & 3.305 \\ {[2.03]^{* *}} & {[0.56]} \\ 2501 & 2207 \\ 0.86 & 0.90\end{array}$

-0.940
$[0.21]$
-9.200
$[1.82]^{*}$
2501
0.85

0.177

[1.32]

0.287

0.215

$[1.86]^{*} \quad[1.98]^{* *}$

$1356 \quad 1401$

Notes: See table 3 
Table 6: Comparing Effects of Hyperactivity, Poor Health, \& Chronic Conditions, Canada

\section{Fixed Effects Regressions}

Panel 1

Hyperactivity Score 1994

Observations

R-squared

Panel 2

Chronic Condition 1994

\# Observations

R-squared

Panel 3

Poor Health in 1994

\# Observations

R-squared

Notes: See table 3

$\begin{array}{ccccc}\text { Delinq. } & \text { Grade Rep. } & \text { Math } & \text { Reading } & \text { Special Ed. } \\ 0.008 & 0.005 & -1.179 & -0.660 & 0.021 \\ {[1.08]} & {[2.46]^{* *}} & {[3.94]^{* *}} & {[2.70]^{* *}} & {[2.95]^{* *}} \\ 2514 & 3923 & 2208 & 2208 & 1357 \\ 0.9 & 0.85 & 0.91 & 0.9 & 0.95\end{array}$

$\begin{array}{ccccc}0.024 & 0.006 & 1.916 & 1.728 & 0.042 \\ {[0.47]} & {[0.45]} & {[0.80]} & {[0.90]} & {[0.76]} \\ 2514 & 3923 & 2208 & 2208 & 1357 \\ 0.9 & 0.85 & 0.91 & 0.9 & 0.95\end{array}$

$\begin{array}{ccccc}0.084 & 0.021 & 0.175 & 0.956 & -0.035 \\ {[1.15]} & {[0.037]} & {[0.05]} & {[0.35]} & {[0.44]} \\ 2511 & 3920 & 2206 & 2206 & 1356 \\ 0.9 & 0.85 & 0.91 & 0.9 & 0.95\end{array}$

0.042
$0.76]$
1357
0.95



0.035
$0.44]$
1356
0.95


Table 7: Interactions of Income With Hyperactivity

\begin{tabular}{|c|c|c|c|c|c|c|c|c|c|c|}
\hline \multirow[b]{3}{*}{ 1. OLS - Income } & [1] & [2] & [3] & [4] & [5] & [6] & [7] & [8] & [9] & [10] \\
\hline & Canada & U.S. & Canada & U.S. & Canada & U.S. & Canada & U.S. & Canada & U.S. \\
\hline & Delinq. & Delinq. & Grade Rep. & Grade Rep. & Math & Math & Reading & Reading & Special Ed. & Special Ed. \\
\hline \multirow[t]{2}{*}{ Interaction } & 0.000 & -0.004 & -0.011 & -0.003 & 0.752 & 0.069 & 0.616 & 0.614 & -0.016 & -0.003 \\
\hline & {$[0.01]$} & {$[0.23]$} & {$[4.16]^{* *}$} & {$[0.49]$} & {$[2.30]^{* *}$} & {$[0.15]$} & {$[2.47]^{* *}$} & [1.25] & {$[2.72]^{* *}$} & {$[0.34]$} \\
\hline \multirow[t]{2}{*}{ Hyperactivity 1994} & 0.015 & 0.014 & 0.012 & 0.005 & -1.758 & -0.896 & -1.164 & -1.428 & 0.031 & 0.009 \\
\hline & {$[3.37]^{* *}$} & {$[1.83]^{*}$} & {$[6.23]^{* *}$} & {$[1.52]$} & {$[8.26]^{* *}$} & {$[3.98]^{* *}$} & {$[6.79]^{* *}$} & {$[5.58]^{* *}$} & {$[7.23]^{* *}$} & {$[2.16]^{* *}$} \\
\hline \multirow{2}{*}{$\begin{array}{l}\text { Average Income } \\
{[100,000]}\end{array}$} & 0.008 & -0.066 & -0.006 & -0.038 & 5.086 & 15.039 & 3.556 & 10.909 & 0.013 & -0.011 \\
\hline & {$[0.33]$} & {$[0.62]$} & {$[0.80]$} & {$[1.45]$} & {$[3.38]^{* *}$} & {$[5.16]^{* *}$} & {$[2.79]^{* *}$} & {$[3.20]^{* *}$} & {$[0.78]$} & {$[0.31]$} \\
\hline Observations & 2516 & 1303 & 3925 & 3240 & 2209 & 2501 & 2209 & 2501 & 1357 & 1401 \\
\hline R-squared & 0.09 & 0.06 & 0.04 & 0.06 & 0.15 & 0.23 & 0.13 & 0.2 & 0.15 & 0.05 \\
\hline \multicolumn{11}{|l|}{ 2. Fixed Effects } \\
\hline \multirow[t]{2}{*}{ Interaction } & 0.024 & -0.033 & -0.013 & 0.001 & 0.195 & 0.107 & -0.625 & 0.581 & -0.004 & -0.021 \\
\hline & [1.02] & {$[0.44]$} & {$[2.58]^{* *}$} & {$[0.06]$} & [0.28] & {$[0.12]$} & [1.11] & {$[0.60]$} & [0.33] & [1.14] \\
\hline \multirow[t]{2}{*}{ Hyperactivity 1994} & -0.006 & -0.002 & 0.012 & 0.004 & -1.295 & -1.041 & -0.289 & -1.083 & 0.024 & 0.018 \\
\hline & {$[0.40]$} & {$[0.08]$} & {$[3.51]^{* *}$} & [0.93] & {$[2.56]^{* *}$} & {$[2.26]^{* *}$} & {$[0.70]$} & {$[2.20]^{* *}$} & {$[2.19]^{* *}$} & {$[1.88]^{*}$} \\
\hline \multirow{2}{*}{$\begin{array}{l}\text { Observations } \\
\text { R-squared }\end{array}$} & 2514 & 1304 & 3923 & 3241 & 2208 & 2501 & 2208 & 2501 & 1357 & 1401 \\
\hline & 0.9 & 0.9 & 0.85 & 0.76 & 0.91 & 0.86 & 0.9 & 0.86 & 0.95 & 0.85 \\
\hline \multicolumn{11}{|c|}{ 3. Fixed Effects - Indicator for Hyperactivity Score $>=90$ th percentile } \\
\hline \multirow[t]{2}{*}{ Interaction } & 0.369 & -0.045 & -0.215 & -0.267 & 0.455 & -16.888 & -9.856 & -6.455 & -0.139 & -0.128 \\
\hline & [1.19] & [0.05] & {$[3.15]^{* *}$} & {$[1.79]^{*}$} & {$[0.05]$} & [1.10] & [1.33] & {$[0.40]$} & [1.02] & {$[0.41]$} \\
\hline \multirow{2}{*}{$\begin{array}{l}\text { Hperactivity Score } 1994 \\
\text { Above 90th percentile }\end{array}$} & -0.285 & 0.132 & 0.178 & 0.155 & -9.732 & 1.824 & -0.220 & -3.556 & 0.466 & 0.17 \\
\hline & [1.52] & {$[0.43]$} & {$[4.21]^{* *}$} & {$[2.86]^{* *}$} & [1.51] & {$[0.31]$} & {$[0.04]$} & {$[0.56]$} & {$[4.11]^{* *}$} & [1.28] \\
\hline Observations & 2514 & 1304 & 3923 & 3241 & 2208 & 2501 & 2208 & 2501 & 1357 & 1401 \\
\hline R-squared & 0.9 & 0.9 & 0.85 & 0.76 & 0.91 & 0.86 & 0.9 & 0.86 & 0.96 & 0.85 \\
\hline
\end{tabular}

Notes: See Table 3.

The first stage F-statistic for test that the parent score and its interaction with income are jointly 0 in our IV models is 79 . 
Table 8: Effects of Hyperactivity in 1994 and Income on Treatment in 1994

\begin{tabular}{|c|c|c|c|c|c|c|c|c|c|c|c|c|}
\hline & [1] & [2] & [3] & [4] & [5] & [6] & [7] & [8] & [9] & [10] & [11] & [12] \\
\hline 1. OLS & $\begin{array}{c}\text { Canada } \\
\text { Drug }\end{array}$ & $\begin{array}{c}\text { Canada } \\
\text { Drug }\end{array}$ & $\begin{array}{c}\text { Canada } \\
\text { Psych. }\end{array}$ & $\begin{array}{l}\text { Canada } \\
\text { Psych. }\end{array}$ & $\begin{array}{c}\text { Canada } \\
\text { Any }\end{array}$ & $\begin{array}{c}\text { Canada } \\
\text { Any }\end{array}$ & $\begin{array}{l}\text { U.S. } \\
\text { Drug }\end{array}$ & $\begin{array}{l}\text { U.S. } \\
\text { Drug }\end{array}$ & $\begin{array}{c}\text { U.S. } \\
\text { Psych. }\end{array}$ & $\begin{array}{c}\text { U.S. } \\
\text { Psych. }\end{array}$ & $\begin{array}{l}\text { U.S. } \\
\text { Any }\end{array}$ & $\begin{array}{l}\text { U.S. } \\
\text { Any }\end{array}$ \\
\hline \multirow[t]{2}{*}{ Hyper Score 1994} & 0.005 & 0.005 & 0.005 & 0.006 & 0.009 & 0.009 & 0.007 & 0.008 & 0.013 & 0.009 & 0.014 & 0.011 \\
\hline & {$[5.85] * *$} & {$[3.89]^{* *}$} & {$[5.35] * *$} & {$[3.49]^{* *}$} & {$[7.44]^{* *}$} & {$[4.73]^{* *}$} & {$[7.02]^{* *}$} & {$[3.12]^{* *}$} & {$[8.78]^{* *}$} & {$[3.36]^{* *}$} & {$[9.53]^{* *}$} & {$[3.90]^{* *}$} \\
\hline \multirow{2}{*}{$\begin{array}{l}\text { Interaction hyper } \\
\text { \& income }\end{array}$} & & -0.001 & & -0.002 & & -0.002 & & 0 & & 0.009 & & 0.008 \\
\hline & & [0.39] & & {$[0.70]$} & & {$[0.58]$} & & {$[0.03]$} & & [1.48] & & {$[1.32]$} \\
\hline \multirow{2}{*}{$\begin{array}{l}\text { Average Income } \\
{[100,000]}\end{array}$} & -0.005 & -0.003 & -0.007 & -0.002 & -0.009 & -0.004 & -0.004 & -0.003 & 0.045 & 0.003 & 0.03 & -0.009 \\
\hline & {$[1.26]$} & {$[0.61]$} & {$[0.81]$} & {$[0.16]$} & {$[1.01]$} & [0.39] & [0.29] & {$[0.16]$} & {$[2.15]^{* *}$} & {$[0.11]$} & [1.35] & {$[0.31]$} \\
\hline \# Observations & 3925 & 3925 & 3920 & 3920 & 3920 & 3920 & 3749 & 3749 & 3745 & 3745 & 3745 & 3745 \\
\hline R-squared & 0.04 & 0.04 & 0.03 & 0.03 & 0.05 & 0.05 & 0.04 & 0.04 & 0.09 & 0.09 & 0.09 & 0.09 \\
\hline \multicolumn{13}{|l|}{ 2. Fixed Effects } \\
\hline \multirow[t]{2}{*}{ Hyper Score 1994} & 0.002 & 0.001 & 0.005 & 0.010 & 0.006 & 0.01 & 0.009 & 0.011 & 0.015 & 0.013 & 0.018 & 0.013 \\
\hline & {$[2.00]^{* *}$} & [0.67] & {$[2.77]^{* *}$} & {$[3.16]^{* *}$} & {$[3.31]^{* *}$} & {$[2.94] * *$} & {$[5.46] * *$} & {$[3.44] * *$} & {$[6.95]^{* *}$} & {$[3.11] * *$} & {$[7.11] * *$} & {$[2.77]^{* *}$} \\
\hline Interaction hyper & & 0.001 & & -0.009 & & -0.007 & & -0.004 & & 0.006 & & 0.012 \\
\hline \& income & & {$[0.49]$} & & {$[1.97]^{* *}$} & & [1.36] & & {$[0.60]$} & & {$[0.75]$} & & {$[1.25]$} \\
\hline \# Observations & 3923 & 3923 & 3918 & 3918 & 3918 & 3918 & 3749 & 3749 & 3745 & 3745 & 3745 & 3745 \\
\hline R-squared & 0.87 & 0.87 & 0.87 & 0.87 & 0.87 & 0.87 & 0.72 & 0.72 & 0.789 & 0.789 & 0.77 & 0.77 \\
\hline
\end{tabular}

Notes: See Table 3. 


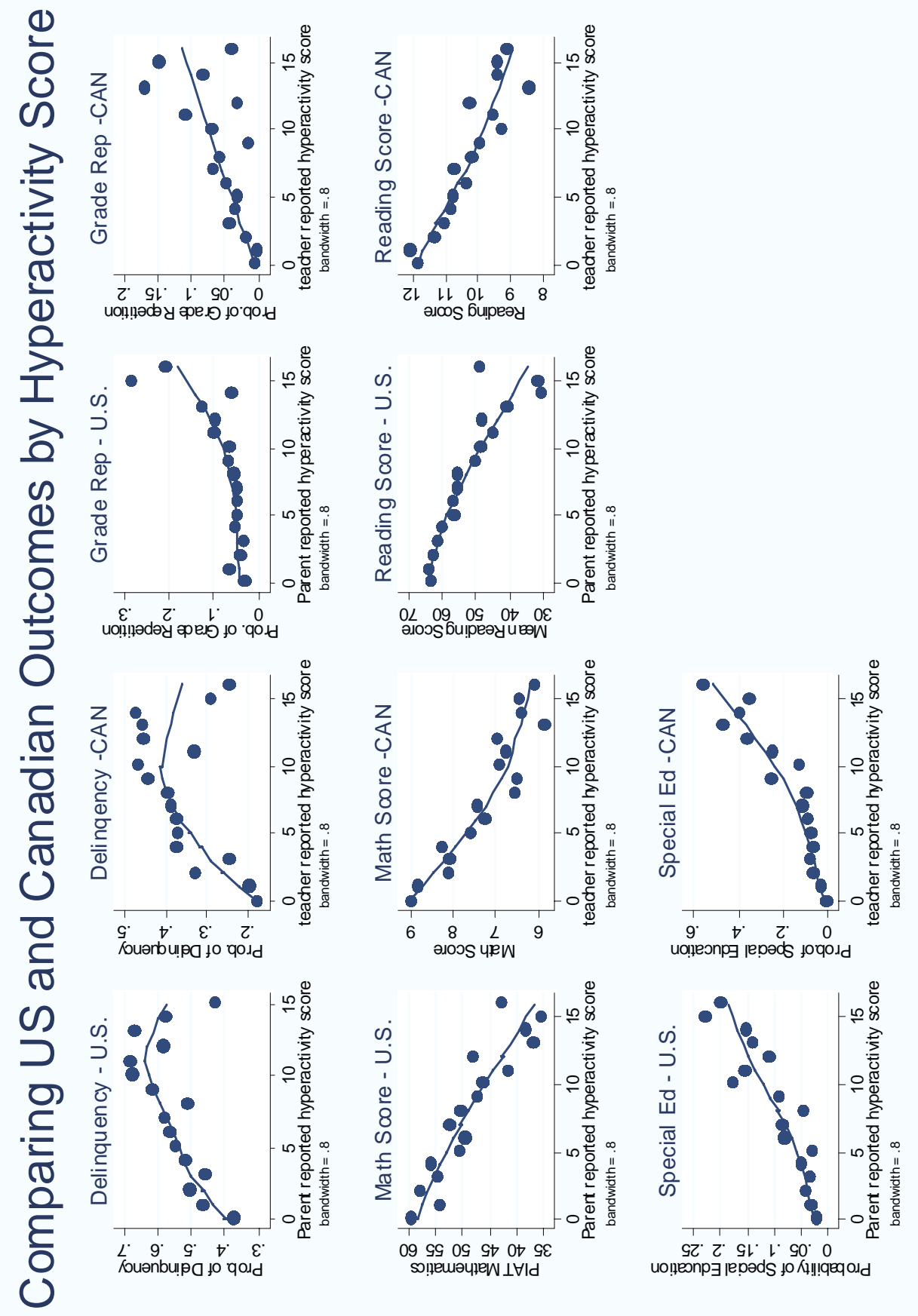

